\title{
Recent Advances in Oxygen Electrocatalysts Based on Perovskite Oxides
}

\author{
Jun $\mathrm{Xu}^{1,+}$, Chan Chen ${ }^{1,+}$, Zhifei Han ${ }^{2}$, Yuanyuan Yang ${ }^{1}$, Junsheng Li ${ }^{1,3, * \mathbb{D}}$ and Qibo Deng ${ }^{2} \mathbb{D}$ \\ 1 Department of Chemistry, School of Chemistry, Chemical Engineering and Life Sciences, \\ Wuhan University of Technology, 122 Luoshi Road, Wuhan 430070, China \\ 2 School of Materials Science and Engineering, Tianjin University of Technology, Tianjin 300384, China \\ 3 Hubei Provincial Key Laboratory of Fuel Cell, Wuhan University of Technology, 122 Luoshi Road, \\ Wuhan 430070, China \\ * Correspondence: li_j@whut.edu.cn \\ + These authors contributed equally to this work.
}

Received: 4 July 2019; Accepted: 12 August 2019; Published: 14 August 2019

\begin{abstract}
Electrochemical oxygen reduction and oxygen evolution are two key processes that limit the efficiency of important energy conversion devices such as metal-air battery and electrolysis. Perovskite oxides are receiving discernable attention as potential bifunctional oxygen electrocatalysts to replace precious metals because of their low cost, good activity, and versatility. In this review, we provide a brief summary on the fundamentals of perovskite oxygen electrocatalysts and a detailed discussion on emerging high-performance oxygen electrocatalysts based on perovskite, which include perovskite with a controlled composition, perovskite with high surface area, and perovskite composites. Challenges and outlooks in the further development of perovskite oxygen electrocatalysts are also presented.
\end{abstract}

Keywords: perovskite oxide; oxygen reduction reaction; oxygen evolution reaction; electrocatalyst

\section{Introduction}

Electrochemical oxygen reduction reaction (ORR) and oxygen evolution reaction (OER) are the key processes in a variety of energy conversion devices such as fuel cells and metal-air batteries [1,2]. Both ORR and OER have high activation barriers that severely limit the overall performance of the energy conversion devices in which ORR/OER are involved. Noble metal-based electrocatalysts have long been used to catalyze ORR (e.g., $\mathrm{Pt}$ ) and $\mathrm{OER}$ (e.g., $\mathrm{IrO}_{2}$ and $\mathrm{RuO}_{2}$ ). However, noble metal electrocatalysts suffer from several inherent limitations. First, precious metal electrocatalysts are susceptible to poisons and tend to aggregate under working conditions, leading to the degradation of performance $[3,4]$. Furthermore, the low availability of noble metals cannot sustain their widespread applications as an electrocatalyst in emerging energy conversion devices [5]. In addition, electrocatalysts are required to have high catalytic activity toward both ORR and OER in some specific applications such as a metal-air battery [6]. The bifunctionality of the noble metal electrocatalysts is not high enough to meet the demand of these devices. Thus, exploration of low-cost and high-performance oxygen electrocatalysts has gained significant research interest recently. Carbon-based electrocatalysts that feature good conductivity, large surface area, and tunable heteroatom content are now shown to be promising oxygen electrocatalysts $[5,7,8]$. For example, a $\mathrm{N}$ and $\mathrm{S}$ co-doped carbon catalyst demonstrated a superior ORR and OER activity that surpassed most of the existing oxygen electrocatalysts [9]. However, the oxidation of carbon materials at anodic conditions leads to the generation of oxygen species on the surface, which will increase the resistance and may eventually give rise to the decomposition of the materials $[10,11]$. Thus, the long-term stability of carbon-based materials in a highly oxidative OER environment is a great challenge. 
An ideal oxygen electrocatalyst should offer proper binding (neither too strong nor too weak) to oxygen species. Transition metal oxides are a class of low-cost material that could provide $\mathrm{d}$ orbital for the binding of oxygen species. Thus, transition metal oxides are considered to be a viable alternative to the traditional precious metal oxygen electrocatalysts. Perovskite oxides with the general formula $\mathrm{ABO}_{3}$ are generally defined as oxides that have the same crystal structure with $\mathrm{CaTiO}_{3}$. Normally, the large-radius rare-earth ions occupy the A-site that are 12-fold coordinated with oxygen ions, while the B-site is occupied by 6 -fold coordinated transition metal ions. A trait of perovskites that differ from other metal oxides such as spinels is their capability of accommodating multiple A-site and B-site cations. This provides an opportunity to finely tune its electronic and catalytic properties [12]. In addition, perovskite oxides allow for partial substitution at the A and/or B position $[13,14]$. This partial substitution can induce changes in the valence states of A- and B-site cations and the generation of oxygen vacancies. These changes in perovskite oxides can be used to engineer the adsorption behavior of reaction intermediate on the material, and thus their catalytic activity can be improved. Furthermore, perovskite oxides are chemically more stable than the carbon-based catalysts under oxidative electrochemical reactions. Although reports on perovskite oxygen electrocatalysts can be dated back to the 1970s [15], perovskites have only recently been recognized as a sort of competitive oxygen electrocatalysts [16,17], which is possibly due to the lack of understanding on the mechanism of the oxygen electrocatalysis. In this review, we aim to cover the advances in active perovskite oxygen electrocatalysts that have recently been reported. The first part of the review focuses on intrinsic ORR/OER activity of perovskite oxides. Subsequently, we discuss emerging perovskite oxygen electrocatalysts that show high ORR/OER activity. Finally, a brief summary and outlook for the future development of advanced perovskite electrocatalysts is provided.

\section{Intrinsic ORR/OER Activity of Perovskite Oxides}

The catalytic mechanism of perovskite oxides is distinct from that of a precious metal catalyst and its ORR/OER activity is mainly attributed to the transition metal site [18-20]. A generally-accepted ORR pathway on a perovskite oxides is shown in Figure 1A,B [16,21]. Briefly, the oxygen atom of an $\mathrm{H}_{2} \mathrm{O}$ molecule is coordinated to the transition metal on the surface, generating surface $\mathrm{M}-\mathrm{OH}^{-}$species. The dissociative adsorption of the oxygen molecule, through either a side-on or an end-on fashion, leads to the oxidation of $\mathrm{M}$ and displacement of surface $\mathrm{OH}^{-}$to $\mathrm{O}_{2}{ }^{2-}$ (Step 1). Surface $\mathrm{O}_{2}{ }^{2-}$ is protonated with $\mathrm{M}$ being reduced (Step 2), followed by the oxidation of $\mathrm{M}$ and formation of surface $\mathrm{O}^{2-}$ (Step 3). Subsequent $\mathrm{O}^{2-} / \mathrm{OH}^{-}$displacement results in the regeneration of surface hydroxide. Step 1 and 4 are thought to be the rate-determining steps. According to this mechanism, the binding strength of oxygen on the perovskite surface influences its ORR performance. It has been pointed out that for a perovskite oxide without structural deformation or distortion, its ORR activity can be correlated with the extent of the overlap between the $\mathrm{e}_{\mathrm{g}}$ orbital of the perovskite and the $\mathrm{sp}_{\sigma}$ orbital of oxygen, and perovskite with a higher overlap integral are generally more active toward ORR [22]. Suntivich et al. examined a series of perovskites in terms of their electronic structure and ORR performance and concluded that one of the main factors determining the ORR activity of the perovskites was the extent of antibonding orbital filling of the transition metal ions [16]. Perovskites with a higher $\mathrm{e}_{\mathrm{g}}$ filling hinder the activation of oxygen and the binding strength of the reaction intermediate while ones with a low $\mathrm{e}_{\mathrm{g}}$ filling inhibit the desorption of the ORR intermediate. An $\mathrm{e}_{\mathrm{g}}$ filling of $\sim 1$ was proposed as the optimal electronic structure for ORR and this criterion was used to guide the rational design of active perovskite ORR catalysts. Although this performance descriptor has been demonstrated in many cases $[23,24], e_{g}$ cannot be used solely to predict the ORR activity of the perovskites as it was found out experimentally that some perovskites with identical e possessed different intrinsic ORR performance [25], which suggests that the bulk electronic status of the perovskites is not an exclusive factor that determines its surface chemical activity. Other factors such as the covalency of the B-O bond [16] also affect the intrinsic ORR activity of perovskite oxides. 
(A)

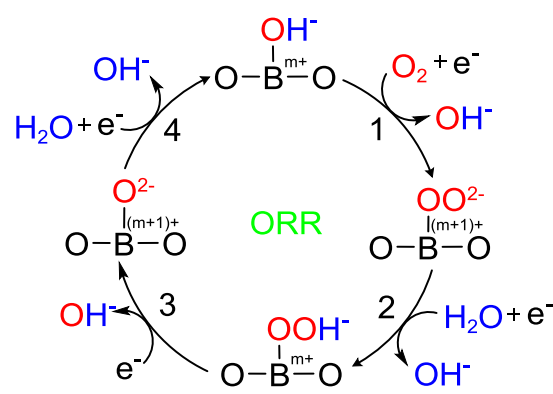

(C)

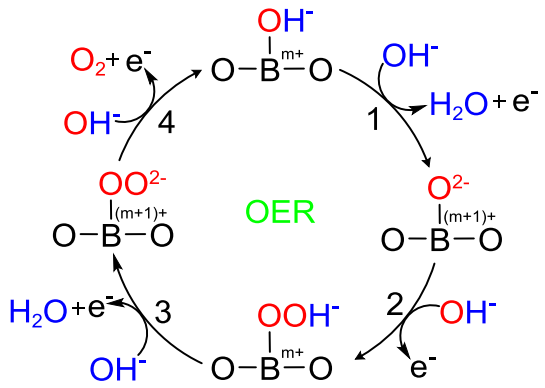

(B)

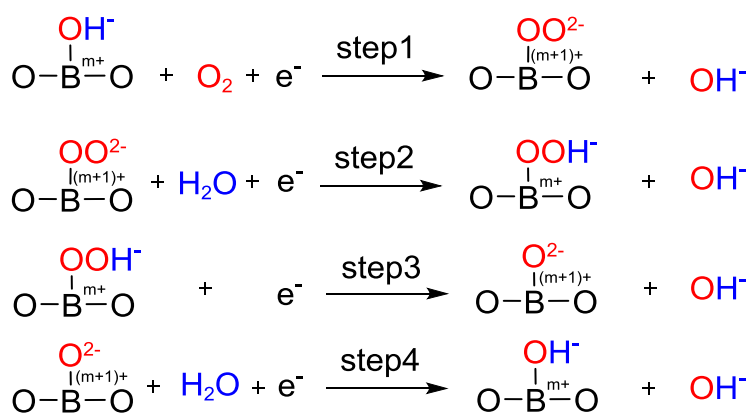

(D)

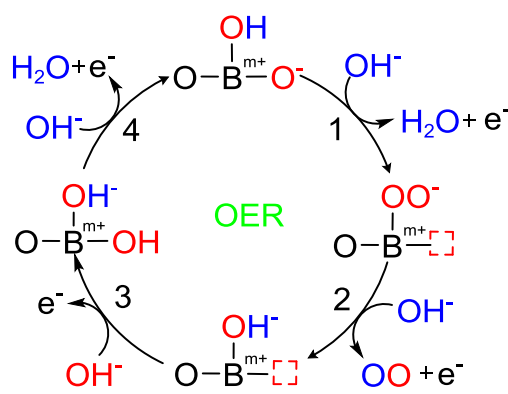

Figure 1. Proposed (A) Oxygen reduction reaction (ORR) mechanism (reproduced from [16], with permission from springer Nature, 2011 ) for perovskite electrocatalysts. (B) the detailed steps of ORR by equations. (C, D) Two different Oxygen evolution reaction (OER) mechanisms proposed for perovskite electrocatalysts (reproduced from [26]).

Likewise, the B-site is also thought to be the main active site of OER and OER is believed to proceed on perovskite oxides in a reverse process with ORR (Figure 1C) [17,27]. Since the eg orbitals of the transition metal ions in perovskite oxides could strongly overlap with the surface oxygen adsorbates [28], the $e_{g}$ filling of a transition metal ion was also considered to be an ideal parameter to describe the intrinsic activity of a perovskite oxide. An e occupancy of $\sim 1$ was identified as optimal for a perovskite oxide OER catalyst [17]. It was found that lattice oxygen in perovskite oxides could also participate in the OER reaction and a new mechanism was suggested recently (Figure 1D) [26,29]. This mechanism is based on the observation that the Co $3 \mathrm{~d}$ band hybridizes with the lattice O $2 \mathrm{p} \pi$ band at an applied potential, which endows the lattice oxygen with OER activity [30].

It should be noted that the structure and intrinsic OER activity of perovskite oxides may evolve with the OER process due to the high potential applied during OER [31-33]. For example, $\mathrm{BaNiO}_{3}$ showed limited initial OER activity. As OER proceeded, a Ni vacancy was generated and a mixed valence of $\mathrm{Ni}$ was formed, leading to the formation of $\mathrm{BaNi}_{0.83} \mathrm{O}_{2.5}$. The calculated $\mathrm{O}$ p-band center of $\mathrm{BaNi}_{0.83} \mathrm{O}_{2.5}$ was $-1.79 \mathrm{eV}$, closer to the Fermi level when compared to that of $\mathrm{BaNiO}_{3}$. In addition, $\mathrm{BaNi}_{0.83} \mathrm{O}_{2.5}$ had an optimized $\mathrm{e}$ filling of 1.4. The surface area normalized activity of $\mathrm{BaNi}_{0.83} \mathrm{O}_{2.5}$ was much higher than that of $\mathrm{BaNiO}_{3}$ [32]. Similarly, $\mathrm{Ba}^{2+}$ and $\mathrm{Sr}^{2+}$ in $\mathrm{Ba}_{0.5} \mathrm{Sr}_{0.5} \mathrm{Co}_{0.8} \mathrm{Fe}_{0.2} \mathrm{O}_{3-\delta}$ (BSCF5582) [17] may also leach out during OER cycles because of the redox reaction between oxygen ions and metal cations caused by the high $\mathrm{O} p$-center relative to the Fermi level $[34,35]$. The leaching out of cations led to the formation of an amorphous surface layer on BSCF, thus decreasing its activity [36].

\section{Active Perovskite Oxygen Electrocatalysts}

\subsection{Perovskite Oxygen Electrocatalysts with Regulated Composition}

Varying the composition of perovskite oxides can adjust their electronic state and crystal structure, thereby affecting their catalytic activity toward ORR and OER. The effect of A-site and B-site cation on the ORR/OER performance of $\mathrm{ABO}_{3}$ type perovskites has been thoroughly investigated and reviewed elsewhere [37-41]. These previous studies suggest the possibility of enhancing the performance of a 
perovskite electrocatalyst through substitution of its A and/or B-site. In this sub-section, we focus on recent studies on perovskite oxides with partial cation substitution or oxygen vacancies.

\subsubsection{Perovskite Electrocatalysts with Partial A-Site Variation}

The perovskite A-site is generally not considered to be the active site that directly participates in the oxygen electrode reactions. However, A-site cations may influence the ORR/OER performance of the perovskite indirectly. It has been demonstrated that the introduction of $\mathrm{Sr}$ into $\mathrm{LaCoO}_{3}$ influences the crystal structure of the perovskite so that the atoms tend to align along the Co-O-Co bond (Figure 2A) [42,43]. Such a configuration in turn causes a higher overlap between the occupied O 2p valence band and unoccupied Co $3 \mathrm{~d}$ band, which increases the intrinsic activity of the perovskite. In addition, incorporation of the $\mathrm{Sr}$ component in the perovskite also leads to the generation of $\mathrm{Co}$ with a higher oxidation state. Due to these effects, the Sr-doped $\mathrm{LaCoO}_{3}$ catalyst showed improved catalytic performance than $\mathrm{LaCoO}_{3}$ (Figure 2B). Similarly, the doping of La into the A-site of BSCF5582 was reported to selectively pose local stress on the Co sublattice octahedron [23]. The comminution of $\mathrm{La}_{0.3}$-BSCF5582 was observed due to the presence of the local stress. In addition, a secondary phase, $\mathrm{LaCoO}_{3-\delta}$, was also generated. Furthermore, Co and Fe were partly oxidized because of the introduction of a higher valence La. These effects all together endowed La $\mathrm{a}_{3}-\mathrm{BSCF}_{582}$ with high ORR activity and superior OER activity, which was 2-3 times higher than the well-known BSCF5582 (Figure 2C,D). Na-doped $\mathrm{SrRuO}_{3}$ improved oxygen evolution activity and durability in acid media [44]. $\mathrm{SrRuO}_{3}$ bound reaction intermediates too strongly while $\mathrm{Na}^{+}$substituted in the $\mathrm{Sr}^{2+}$ position not only stabilized the structure, but also increased the oxidation state of Ru so that it could positively shift the position of the $\mathrm{O}$ p-band and $\mathrm{Ru}$ d-band centers, impairing the bonds between $\mathrm{Ru}$ and oxygen species, which showed high OER activity and durability.

(A)

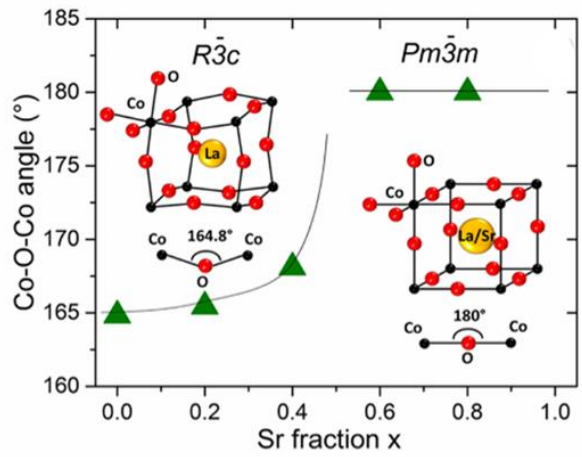

(C)

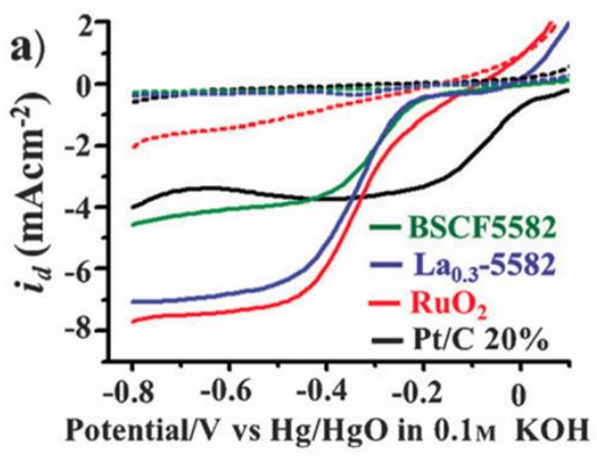

(B)

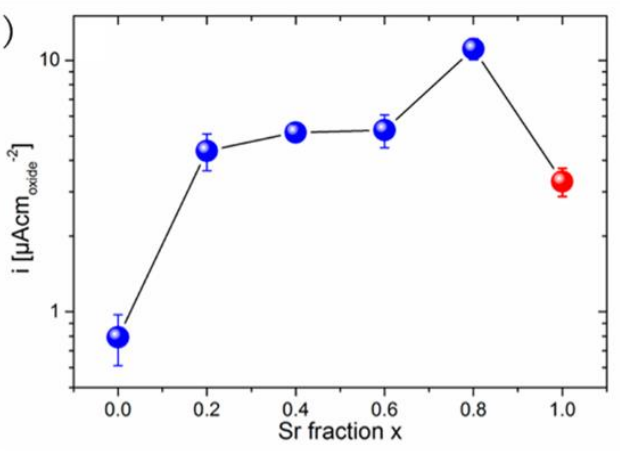

(D)

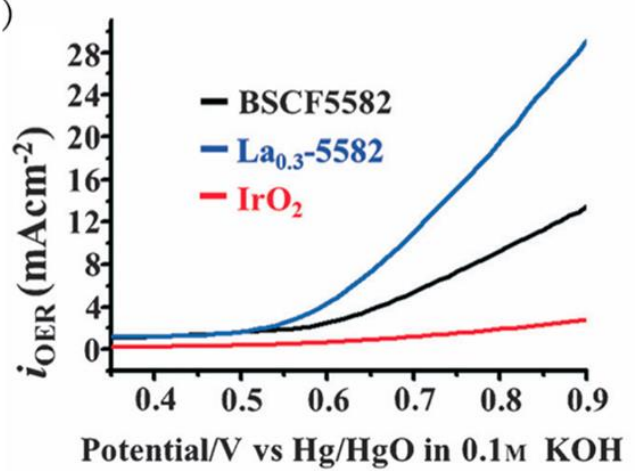

Figure 2. (A) The $\mathrm{Co}-\mathrm{O}-\mathrm{Co}$ angle in $\mathrm{La}_{1-\mathrm{x}} \mathrm{Sr}_{\mathrm{x}} \mathrm{CoO}_{3}$ as a function of Sr content (adapted from [43], with permission from American Chemical Society, 2015). (B) OER current density (in $\mu \mathrm{A} \mathrm{cm}_{\text {oxide }^{-2}}$ ) of the $\mathrm{La}_{1-x} \mathrm{Sr}_{\mathrm{x}} \mathrm{CoO}_{3}$ series; the red circle represents $\mathrm{SrCoO}_{2.5}$ (adapted from [43], with permission from American Chemical Society, 2015). (C) ORR and (D) OER performance of KB supported $\mathrm{La}_{0.3}\left(\mathrm{Ba}_{0.3} \mathrm{Sr}_{0.5}\right)_{0.7} \mathrm{Co}_{0.8} \mathrm{Fe}_{0.2} \mathrm{O}_{3-\delta}$ in $0.1 \mathrm{M} \mathrm{KOH}$ solution at $1600 \mathrm{rpm}$ with a scan rate of $10 \mathrm{mV} \mathrm{s}^{-1}$ (adapted from [23], with permission from John Wiley and Sons, 2014). 
Partial substitution of A-sites in $\mathrm{BaCoO}_{3-\delta}$ with lanthanides ( $\mathrm{Pr}, \mathrm{Sm}, \mathrm{Gd}, \mathrm{Ho}$, and Ln) have been shown to enhance the activity and the durability of the perovskites [45]. The $\mathrm{e}_{\mathrm{g}}$ filling of the substituted perovskite, $\mathrm{Ln}_{0.5} \mathrm{Ba}_{0.5} \mathrm{CoO}_{3-\delta}$, was estimated to be $\sim 1$, which might explain its superior OER activity. DFT studies revealed that the $\mathrm{O} p$-band center of $\mathrm{Ln}_{0.5} \mathrm{Ba}_{0.5} \mathrm{CoO}_{3-\delta}$ was close to the Fermi level, which is important for the high activity and stability of the catalyst. In another study, a partial substitution of $\mathrm{Ba}$ in $\mathrm{PrBaCO}_{2} \mathrm{O}_{5+\delta}$ with $\mathrm{Sr}$ was proven to modulate the surface $\mathrm{Co}^{4+}$ concentration [46]. The electrophilic surface $\mathrm{Co}^{4+}$ facilitates the formation of surface $\mathrm{O}-\mathrm{OH}$ and the deprotonation of surface adsorbed OOH species [47], thereby improving the OER activity of the perovskite. The ORR activity of Sr-doped $\mathrm{PrBaCO}_{2} \mathrm{O}_{5+\delta}$ was also enhanced due to the improved $\mathrm{O}_{2}$ adsorption on the oxide surface with high concentration $\mathrm{Co}^{4+}$.

While substitution of A-site elements with a higher valence ion is an effective approach to enhance its electrochemical performance, a high degree of A-site substitution may cause the breakdown of the perovskite structure. Gobaille-Shaw et al. synthesized $\mathrm{La}_{1-x} \mathrm{Ba}_{x} \mathrm{MnO}_{3}$ nanoparticles through a highly versatile ionic-liquid based method. The ORR activity showed a significant dependence on the bulk Ba content and the best catalytic performance was obtained for $x=0$ and 0.15 [48]. To obtain the stable perovskite oxides with the optimal electronic configuration, the substitution process was coupled with a hydrogenation treatment [49]. $\mathrm{Yb}$-doped $\mathrm{CaMnO}_{3}\left(\mathrm{Ca}_{0.9} \mathrm{Yb}_{0.1} \mathrm{MnO}_{3}, \mathrm{CYM}\right)$ were treated in a $\mathrm{H}_{2} / \mathrm{Ar}$ atmosphere at different temperatures from $320^{\circ} \mathrm{C}$ to $400^{\circ} \mathrm{C}$. CYM hydrogenated at $350{ }^{\circ} \mathrm{C}$ had OER activity, which was judged by the OER current density at an overpotential of $500 \mathrm{mV}$, about 100 times higher than that of the pristine CYM, demonstrating the efficacy of the hydrogenation treatment. The excellent OER performance of the hydrogenated CYM was attributed to its appropriated $e_{g}$ filling and high electron conductivity.

\subsubsection{Perovskite Electrocatalysts with Partial B-Site Variation}

Since B-site directly participates in oxygen redox reactions, the B-site replacement is a simple and effective way to control the ORR/OER activity of a perovskite catalyst [50-52]. Through partial substitution of B-site in $\mathrm{SrTiO}_{3-\delta}$ with the transitional metal element $(\mathrm{M}=\mathrm{Co}$ or $\mathrm{Fe})$, the active perovskite catalyst can be obtained [53]. When Co was used as the B-site element, the OER activity of the substituted $\mathrm{SrCo}_{0.9} \mathrm{Ti}_{0.1} \mathrm{O}_{3-\delta}$ approached that of BSCF. In addition, a better durability was demonstrated for $\mathrm{SrCo}_{0.9} \mathrm{Ti}_{0.1} \mathrm{O}_{3-\delta}$. The good OER performance of $\mathrm{SrM}_{0.9} \mathrm{Ti}_{0.1} \mathrm{O}_{3-\delta}$ stems from its optimized $\mathrm{e}_{\mathrm{g}}$ filling ( 1.16). Furthermore, the low $\mathrm{Co}-\mathrm{O}$ bond strengthens, which facilitates the formation of the redox-active oxygen vacancy and could also contribute to its high activity. Subiao Liu et al. first reported Co-doping layered perovskite $\mathrm{LaSr}_{3} \mathrm{Co}_{\mathrm{m}} \mathrm{Fe}_{3-\mathrm{m}} \mathrm{O}_{10-\delta}$ (LP-LSCF, $\mathrm{m}=0.0,1.0$, $1.5,2.0)$ that displayed superior OER performance in alkaline solution. Its excellent performance can be attributed to the fact that $\mathrm{Co}^{3+}$ partially changed to $\mathrm{Co}^{4+}$ in the surface of $\mathrm{LaSr}_{3} \mathrm{Co}_{1.5} \mathrm{Fe}_{1.5} \mathrm{O}_{10-\delta}$ and greatly generated the oxygen species $\mathrm{O}_{2}{ }^{2-} / \mathrm{O}^{-}$and the $\mathrm{O}$ p-band center was closed to the Fermi level, which shifted the adsorption of $\mathrm{OH}^{-}$and the desorption of $\mathrm{O}_{2}$. The noticeable OER performance gives this layered perovskite $\mathrm{LaSr}_{3} \mathrm{Co}_{1.5} \mathrm{Fe}_{1.5} \mathrm{O}_{10-\delta}$ its promising potential for application in energy conversion and storage [54]. It was presented that the synergistic effect between two kinds of transition metal ions enhances not only the ORR and OER activity, but also the stability when Ni-doped in the $\mathrm{LaCoO}_{3}$ perovskites, with existing $\mathrm{Co}^{3+} / \mathrm{Co}^{2+}$ and $\mathrm{Ni}^{3+} / \mathrm{Ni}^{2+}$ changing the $\mathrm{OH}^{-}$adsorption and $\mathrm{O}_{2}$ desorption [55]. Moreover, to improve the bifunctionality of $\mathrm{La}_{0.2} \mathrm{~S}_{0.8} \mathrm{MnO}_{3}$ (LSM), Ni was doped into the B-sites (Figure 3A) [56]. The resulting $\mathrm{La}_{0.8} \mathrm{Sr}_{0.2} \mathrm{Mn}_{0.6} \mathrm{Ni}_{0.4} \mathrm{O}_{3}$ catalyst showed enhanced ORR (Figure 3B) and OER (Figure 3C) performance. The gap between OER potential (@i=5 mA cm${ }^{-2}$ ) and OER potential (@ $\mathrm{i}=-1 \mathrm{~mA} \mathrm{~cm}^{-2}$ ) decreased by $\sim 0.23 \mathrm{~V}$ when compared to LSM. This performance improvement in part originates from the formation of an oxygen vacancy due to the Ni doping. On the other hand, Ni doping also increased the surface area of the perovskite. Furthermore, Ni doping of LSM may also increase the conductivity of the perovskite oxide [57]. Using the $e_{g}$ descriptor, Zhu et al. synthesized B-site substituted $\mathrm{SrNb}_{0.1} \mathrm{Co}_{0.7} \mathrm{Fe}_{0.2} \mathrm{O}_{3-\delta}$ (SNCF) perovskite [58]. Apart from its near unity $\mathrm{e}_{\mathrm{g}}$ filling, SNCF also featured small charge-transfer resistance, good $\mathrm{OH}^{-}$adsorption, 
and oxygen desorption abilities. These beneficial features make SNCF an attractive OER catalyst over $\mathrm{IrO}_{2}$ and BSCF. $\mathrm{Nb}$ was introduced into the $\mathrm{Mn}$ site of $\mathrm{CaMnO}_{3}(\mathrm{CMO})$ to activate the bifunctional electrocatalysis in both OER and ORR. After being treated with $\mathrm{H}_{2}, \mathrm{CaMn}_{0.75} \mathrm{Nb}_{0.25} \mathrm{O}_{3-\delta}\left(\mathrm{H}_{2}-\mathrm{CMNO}\right)$ held its structure as $\mathrm{CMO}$ while exhibiting a reduced overpotential, a smaller Tafel slope, robust activity, and stability. Moreover, $\mathrm{H}_{2}-\mathrm{CMNO}$ displayed excellent ORR performance with a higher efficiency in electron-transfer when compared to CMO. This great improvement was ascribed to the stable bulk phase, appropriate $e_{g}$ filling, and increased conductivity [59].

(A)

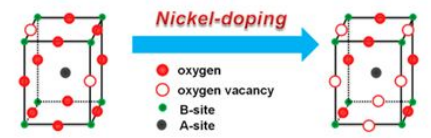

(B)

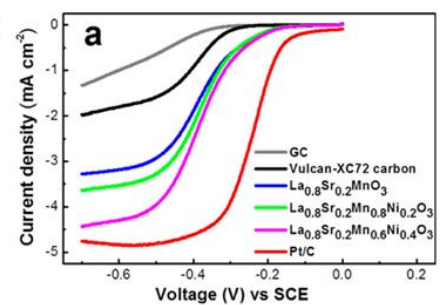

(C)

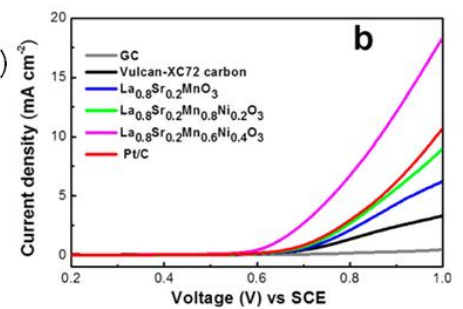

(D)

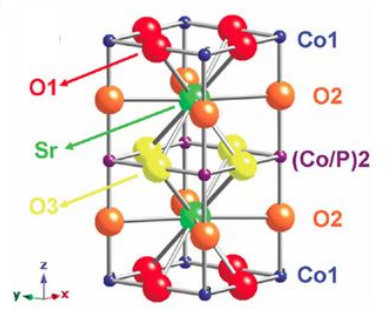

(F)

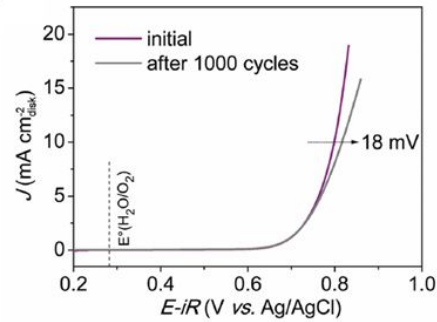

(E)
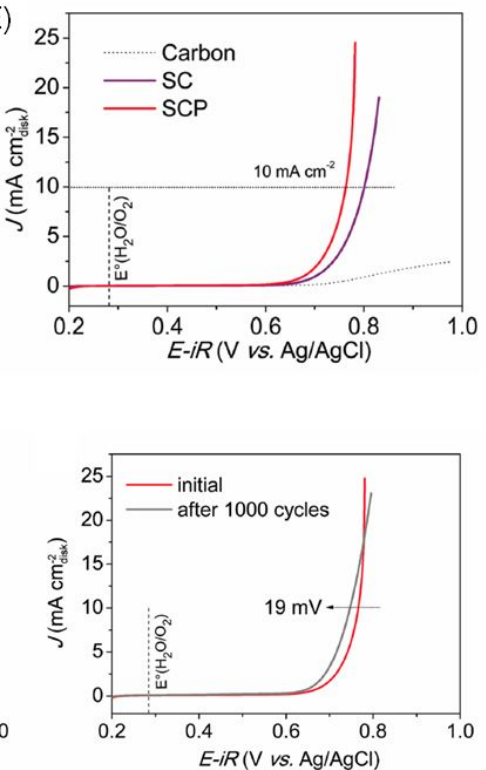

Figure 3. (A) Scheme showing the $\mathrm{Ni}$ doping on $\mathrm{La}_{0.8} \mathrm{Sr}_{0.2} \mathrm{MnO}_{3}$ (adapted from [56], with permission from American Chemical Society, 2016). (B) ORR and (C) OER performance of $\mathrm{La}_{0.8} \mathrm{Sr}_{0.2} \mathrm{Mn}_{0.6} \mathrm{Ni}_{0.4} \mathrm{O}_{3}$ in $\mathrm{O}_{2}$-saturated 0.1 M KOH (adapted from [56], with permission from American Chemical Society, 2016) (D) Scheme showing the tetragonal crystal structure of $\mathrm{SrCo}_{0.95} \mathrm{P}_{0.05} \mathrm{O}_{3-\delta}$ (SCP) (adapted from [60], with permission from John Wiley and Sons, 2016). (E) OER performance of SCP and $\mathrm{SrCoO}_{3-\delta}$ (SC) in $\mathrm{O}_{2}$ saturated $0.1 \mathrm{M} \mathrm{KOH}$ solution with a scan rate of $5 \mathrm{mV} \mathrm{s}^{-1}$ at $1600 \mathrm{rpm}$ (adapted from [60], with permission from John Wiley and Sons, 2016). (F) OER LSV curves of CP (left) and SCP (right) before and after accelerating degradation tests (adapted from [60], with permission from John Wiley and Sons, 2016).

Non-metal element B-site doping of perovskite oxides was recently introduced to enhance the OER activity of perovskite catalysts. Zhu et al. synthesized $\mathrm{SrCo}_{0.95} \mathrm{P}_{0.05} \mathrm{O}_{3-\delta}$ (SCP) (Figure 3D) and investigated its OER activity and electrochemical durability [60]. The potential required to generate an OER current of $10 \mathrm{~mA} \mathrm{~cm}{ }^{-2}$ was only $0.48 \mathrm{~V}$ for SCP (Figure 3E), lower than that for its counterpart without $\mathrm{P}$ doping and other active perovskite catalysts. The significantly improved electric conductivity and a large number of reactive oxygen species caused by $\mathrm{P}$ doping were shown to be the primary cause for the improvement in activity. Moreover, the authors demonstrated that the activity of SCP increased after an accelerated durability test (Figure 3F), which was believed to be induced by the formation of an A-site deficient structure and enlarged electrochemical surface area during the test. This novel substitution strategy is important and may be used for the further rational design of perovskite electrocatalysts. Zhishan Li et al. [61] developed efficient and stable bifunctional OER and ORR catalysts in alkaline electrolyte solutions by phosphorus-doping in $\mathrm{LaFeO}_{3-\delta}$ (LF) perovskite oxide. The enhanced catalytic activity was demonstrated to originate from the vast amount of reactive oxygen species $\left(\mathrm{O}_{2}{ }^{2-} / \mathrm{O}^{-}\right.$species $)$, a trace amount of $\mathrm{Fe}^{4+}$ species, which could facilitate the adsorption of $\mathrm{O}_{2}$ and hydroxyl groups on active sites and optimal $e_{\mathrm{g}}$ orbital filling $\left(\mathrm{t}_{2 \mathrm{~g}}{ }^{3} \mathrm{e}_{\mathrm{g}}{ }^{1}\right)$ as results of the P-doping. Furthermore, the stability boosted due to the incorporation of the high-valence $\mathrm{P}^{5+}$ cations on the Fe-site in LF. 


\subsubsection{Perovskite Electrocatalysts with Controlled Oxygen Deficiency}

The surface reactivity of perovskite oxides can be influenced by their oxygen vacancies. A $\mathrm{RuO}_{2} / \mathrm{La}_{0.9} \mathrm{Fe}_{0.92} \mathrm{Ru}_{0.08} \mathrm{O}_{3}$ composite by fractional $\mathrm{Ru}$-substituted A-site deficient perovskite revealed a better OER activity than the pure LFRO, the conductivity of which was vastly improved through creating the deficiency [62]. One approach to introducing oxygen vacancies is to generate A-site deficiency in the oxides $[63,64]$. As low valence $\mathrm{Sr}$ was doped into the lattice of $\mathrm{LaCoO}_{3}$, the oxidation of Co was increased to achieve electroneutrality and the overlap of the Co $3 \mathrm{~d} / \mathrm{O} 2 \mathrm{p}$ band was facilitated, which further led to the generation of ligand hole/oxygen vacancy (Figure 4A) [26]. The concentration of oxygen vacancies was experimentally found to increase with the extent of the Sr doping level. To examine the effect of oxygen vacancies on its OER activity, a family of $\mathrm{La}_{1-\mathrm{x}} \mathrm{Sr}_{\mathrm{x}} \mathrm{CoO}_{3-\delta}$ catalysts (LSCO, $x=0,0.2,0.4,0.6,0.8,1.0)$ were synthesized. The oxygen diffusion rate of LSCO determined from chronoamperometric studies increased with $\mathrm{Sr}$ substitution. A good correlation between the OER activity of LSCO and its oxygen vacancy concentration/oxygen mobility was identified (Figure 4B). $\mathrm{SrCoO}_{2.7}$, with La fully substituted with $\mathrm{Sr}$, showed the highest intrinsic OER activity, which was two times higher than that of BSCF. Oxygen vacancies can be also introduced into perovskite oxides simply through heat treatment. Chen et al. showed that oxygen-deficient $\mathrm{BaTiO}_{3-\mathrm{x}}$ could be synthesized by heating the sol-gel precursor at $1300{ }^{\circ} \mathrm{C}$ under vacuum [65]. The formation of oxygen vacancies was believed to be associated with the low $\mathrm{O}_{2}$ partial pressure during the heat treatment. The formation of oxygen vacancies may also cause $\mathrm{Ba}$ deficiency due to charge compensation. The as-formed $\mathrm{BaTiO}_{3-x}$ showed a higher ORR and OER performance than the stoichiometric $\mathrm{BaTiO}_{3}$ as the oxygen vacancies could actively participate in the oxygen electrode reactions. The reductive hydrogenation process was also reported to generate oxygen-deficient perovskite oxides. For instance, $\mathrm{CaMnO}_{2.5}$ was synthesized by the hydrogenation of $\mathrm{CaMnO}_{3}$ [66]. On one hand, the $\mathrm{Mn}^{3+}$ in $\mathrm{CaMnO}_{2.5}$ has an electronic configuration of $\mathrm{e}_{\mathrm{g}}=1$, which is favorable for OER. On the other hand, oxygen vacancies also promoted the adsorption of $\mathrm{OH}^{-}$during OER. Therefore, the produced $\mathrm{CaMnO}_{2.5}$ showed a more enhanced OER performance over $\mathrm{CaMnO}_{3}$. Additionally, a functional design for S-doped $\mathrm{CaMnO}_{3}(\mathrm{CMO} / \mathrm{S})$ nanotubes was obtained by controlled sulfur content and oxygen vacancies formed by electrospinning, heat calcination, and sulfurization treatment. The oxygen vacancies produced by S-doping contributed to the remarkable catalytic properties including excellent performance and long-term stability, which showed great potential in practical application in rechargeable metal-air batteries [67].

(A)

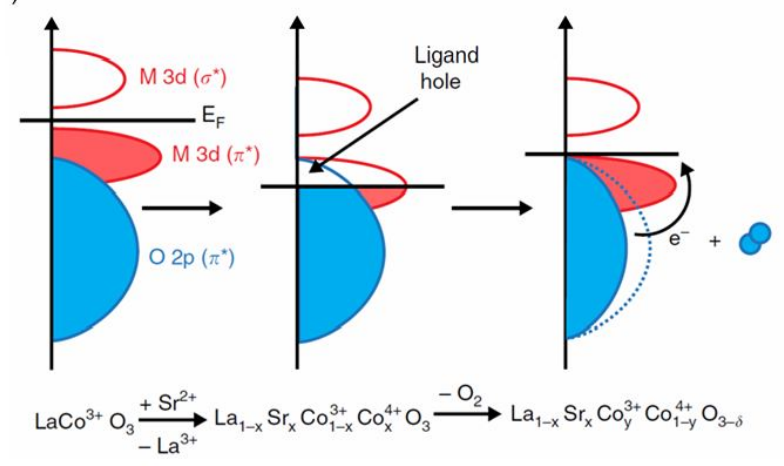

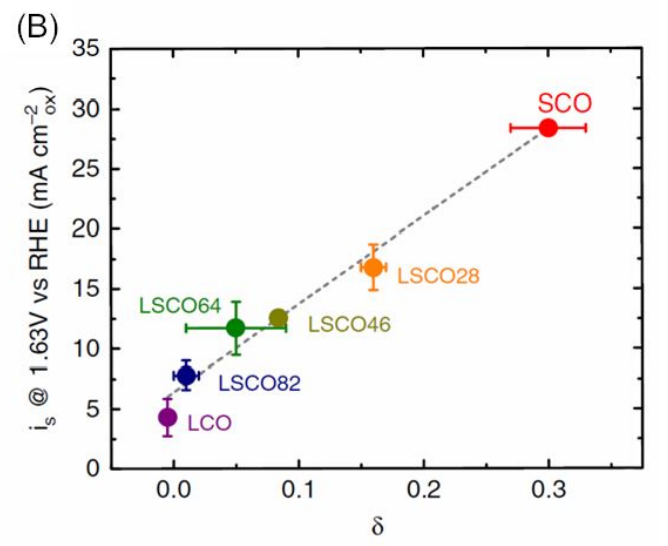

Figure 4. (A) Scheme showing the presence of oxygen vacancies with the introduction of $\mathrm{Sr}$ in $\mathrm{LaCoO}_{3}$ (adapted from [26]). (B) Specific OER activity of $\mathrm{La}_{1-x} \mathrm{Sr}_{\mathrm{x}} \mathrm{CoO}_{3-\delta}$ and $\mathrm{IrO}_{2}$ at $1.63 \mathrm{~V}$ (vs. RHE) (adapted from [26]).

Bin Hua et al. reported a cation-ordered double perovskite oxide with great stability and activity in both ORR and OER, in other words, $\operatorname{PrBa}_{0.85} \mathrm{Ca}_{0.15} \mathrm{MnFeO}_{5+\delta}$. The unique structure could not only provide ordered oxygen vacancy channels, but also furnished advisable numbers of surface oxygen 
defects. Additionally, the proper doping of iron maintained the B-site metals at a high valence with optimal e fillings [68].

Oxygen vacancies in perovskite thin film can be controlled by tensile strain induced by lattice mismatch between the perovskite film and the substrate [69]. Le Wang et al. figured out that compressive strain was favorable while tensile strain was unfavorable when oxygen vacancies were negligible. However, as the tensile strain increased to promote the formation of oxygen vacancies, it enabled an increase in OER [70]. A series of $\mathrm{SrCoO}_{3-\delta}(0 \leq \delta \leq 2.5)$ (SCO) thin films were synthesized by introducing a strain ranging from 1.0 to $4.2 \%$ [71]. Electrochemical measurements showed that the oxygen vacancies generated from the strain control were highly stable under oxidative OER conditions, which was in contrast to the previous report on the instability of $\mathrm{SrCoO}_{3-\delta}$ prepared from the solid state synthesis [72]. $\mathrm{SrCoO}_{3-\delta}$ perovskite thin film with a higher strain showed a higher concentration of oxygen vacancies and exhibited a higher OER activity. The optimal SCO catalyst exhibited an OER activity comparable to that of the $\mathrm{IrO}_{2}$ thin film. Recently, it was further shown that even a small compressive strain induced e splitting of $\mathrm{LaNiO}_{3}$, thus significantly enhancing its ORR and OER activity [73].

\subsection{Perovskite Electrocatalysts with High Surface Area}

Aside from its intrinsic catalytic activity, the porosity of the catalysts is also crucial for its actual performance because the porosity directly influences their active site exposure and transport of reactants/products $[74,75]$. The perovskite catalyst was routinely synthesized through high-temperature calcination of pre-mixed metal precursors at a solid state. Such a sintering reaction normally yields bulk perovskite with a very low surface area. A low surface area would not only limit the utilization of the active sites of the catalyst, but also restrict the wetting of the electrode by the electrolyte in battery applications. Moreover, the constrained ion transportation and electron transfer in a low surface area electrode may further decrease the battery performance of perovskite oxides. Various approaches have been explored for the preparation of perovskites with a higher surface area [76]. Sol-gel synthesis is a widely adopted method. In a typical sol-gel synthesis, a mixture solution of the precursor is first formed and the $\mathrm{pH}$ of the mixture solution is finely controlled to assist the reaction of the precursors. Gel products are obtained as the reaction proceeds. Calcination of the precipitants from the gel products yields the formation of the final perovskite products. Although the sol-gel derived perovskites generally show a higher surface area than that from the solid-state reaction, their particle sizes are still limited mainly to the sub-micron scale. A further decrease in the particle size is expected to boost its catalytic activity due to the enhanced active site exposure and mass transport.

A modified sol-gel method for the preparation of large surface area perovskite was reported by Zhuang et al. [77]. In their synthesis, activated carbon was used as porogen and pre-mixed with a citric acid solution. Corresponding metal precursors were added into the mixture solution for the formation of a gel. After drying, the gel was calcined to produce the high surface area $\mathrm{La}_{0.6} \mathrm{Ca}_{0.4} \mathrm{CoO}_{3}$ (LCC). A LCC catalyst with a surface area of $210 \mathrm{~m}^{2} \mathrm{~g}^{-1}$ was obtained. Such a huge surface area endowed the LCC with excellent ORR/OER bifunctionality. Downsizing the perovskite oxide to tens of nanometers was demonstrated with the hydrothermal assisted synthesis [78]. A hydrothermal assisted synthesis was reported to fabricate high surface area $\mathrm{La}_{0.9} \mathrm{Sr}_{0.1} \mathrm{CoO}_{3}$ (Figure 5A) [79]. It was shown that the morphology of the LSCO could be controlled by changing the solvent used in the hydrothermal synthesis. When a hybrid solvent composed of ethanol and water was used, multi-shelled LSCO nanoparticles with a surface area up to $23.82 \mathrm{~m}^{2} \mathrm{~g}^{-1}$ were prepared. In contrast, the LSCO nanoparticles prepared with the conventional sol-gel method had a surface area of only $11.65 \mathrm{~m}^{2} \mathrm{~g}^{-1}$.

Jung et al. demonstrated that doping and heat treatment could be used to enhance the surface area of the perovskite in the case of La-doped $\mathrm{Ba}_{0.5} \mathrm{Sr}_{0.5} \mathrm{Co}_{0.8} \mathrm{Fe}_{0.2} \mathrm{O}_{3-\delta}$ (BSCF) perovskite (Figure 5B) [80]. The calcination temperature influenced the phase of the resulting perovskite and a uniform cubic perovskite phase could be formed in a certain temperature range. It was also suggested that particle growth was suppressed at a higher La doping level because the diffusion required for ion migration was 
inhibited. $\mathrm{La}_{0.7} \mathrm{BSCF}$ synthesized at $700^{\circ} \mathrm{C}$ exhibited a BET area of $21.3 \mathrm{~m}^{2} \mathrm{~g}^{-1}$. Due to the combination of a high surface area and unique electronic structure, $\mathrm{La}_{0.7} \mathrm{BSCF}$ possessed excellent ORR and OER activity and a superior $\mathrm{Zn}$-air battery performance compared to the $20 \% \mathrm{Pt} / \mathrm{C}$ catalyst. To increase the surface area of a perovskite catalyst, the electrospun technique was used (Figure 5C) [81-83]. Highly porous $\mathrm{La}_{0.5} \mathrm{Sr}_{0.5} \mathrm{Co}_{0.8} \mathrm{Fe}_{0.2} \mathrm{O}_{3}$ (LSCF) nanorods with a surface area of $36.5 \mathrm{~m}^{2} \mathrm{~g}^{-1}$ have been reported [82]. When coupled with nitrogen-doped graphene, the LSCF nanorod exhibited a comparable ORR performance and better OER performance when compared to the commercial $\mathrm{Pt} / \mathrm{C}$ catalyst. The superior stability of the composite was also demonstrated. Hierarchically structured $\mathrm{La}_{0.5} \mathrm{Sr}_{0.5} \mathrm{CoO}_{3-x}$ with both mesopores and macropores were also synthesized and used for a $\mathrm{Li}-\mathrm{O}_{2}$ battery [83]. Dai et al. reported perovskite oxides $\mathrm{LaFeO}_{3}$ (LF) through building 3D ordered macroporous (3DOM) architecture in combination with bulk lattice doping. The open and interconnected 3DOM structure led to a high specific area $\left(20 \mathrm{~m}^{2} \mathrm{~g}^{-1}\right)$, which also increased the number of active sites and facilitated mass transfer. A small amount of iron substitution with cobalt in the oxide lattice (3DOM-LaFe ${ }_{0.8} \mathrm{Co}_{0.2} \mathrm{O}_{3} / \mathrm{LFC} 82$ ) further promoted the catalytic ability and durability in OER [84].

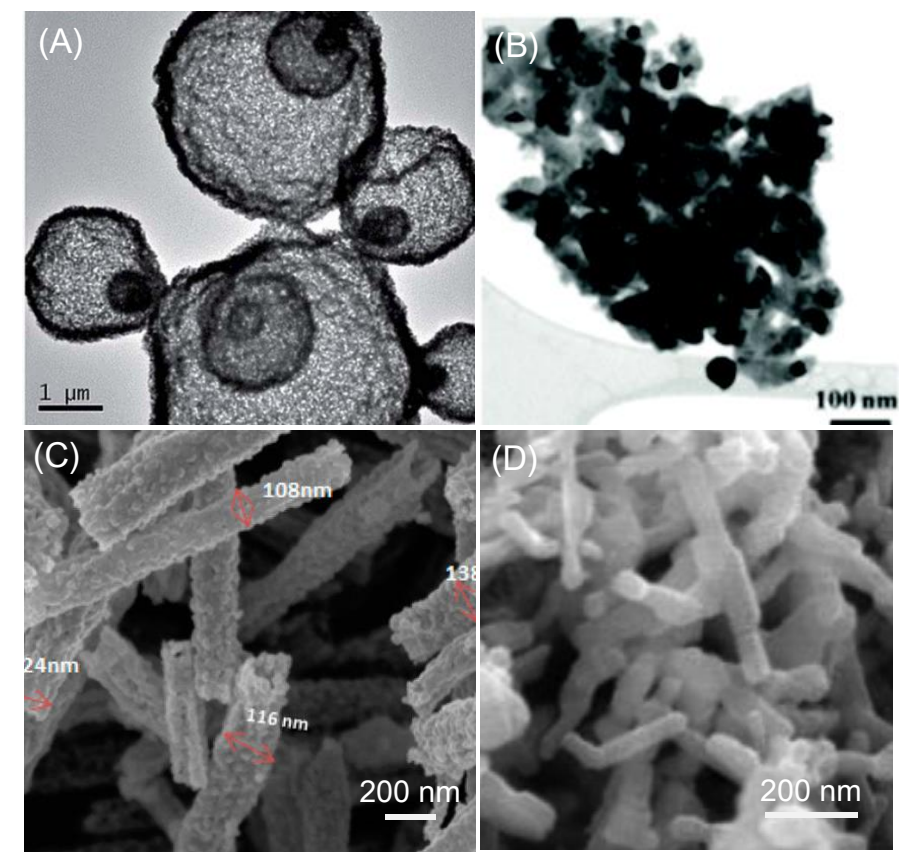

Figure 5. Examples of perovskite oxide electrocatalyst with a large surface area. (A) TEM image of multi-shelled $\mathrm{La}_{0.9} \mathrm{Sr}_{0.1} \mathrm{CoO}_{3}$ with a high surface area (adapted from [79], with permission from Royal Society of Chemistry, 2015). (B) TEM image of La-doped $\mathrm{Ba}_{0.5} \mathrm{Sr}_{0.5} \mathrm{Co}_{0.8} \mathrm{Fe}_{0.2} \mathrm{O}_{3-\delta}$ with an average diameter of $\sim 50 \mathrm{~nm}$ (adapted from [80], with permission from RSC Publishing, 2015). (C) SEM image of a high surface area $\mathrm{La}\left(\mathrm{Co}_{0.71} \mathrm{Ni}_{0.25}\right)_{0.96} \mathrm{O}_{3-\delta}$ nanorod prepared by electrospinning (reproduced from [81], with permission from American Chemical Society, 2016). (D) SEM image of microporous $\mathrm{La}_{0.8} \mathrm{Sr}_{0.2} \mathrm{MnO}_{3}$ nanorod synthesized with a self-assembly assisted method (reproduced from [85], with permission from Elsevier, 2015).

$\mathrm{Lu}$ et al. presented a self-assembly method to prepare $\mathrm{La}_{0.8} \mathrm{Sr}_{0.2} \mathrm{MnO}_{3}$ (LSM) nanorods with numerous defects and high surface area $\left(20.6 \mathrm{~m}^{2} \mathrm{~g}^{-1}\right)$ by using cetrimonium bromide (CTAB) as the soft template (Figure 5D) [85]. Benefiting from the high porosity, the LSM nanorods showed improved electrocatalytic activity toward both ORR and OER compared to the LSM nanoparticles derived from the sol-gel method. Yang et al. reported a graphene/meso-LaSrMnO composite using a surfactant as the structure-directing agent [86]. This novel composite contains both mesopores (in LaSrMnO) and macropores (between the nanosheets) and thus allows for efficient ion transportation and ion diffusion during battery operation. In addition, the composite is more mechanically robust when compared to 
the traditional electrode based on perovskite nanoparticles. The $\mathrm{Li}-\mathrm{O}_{2}$ battery assembled with the graphene/meso-LaSrMnO composite showed both high discharge capacity and cycling performance.

Recently, it was found that changing the porosity of perovskite oxides may alert its electronic state. In the case of $\mathrm{LiCoO}_{2}(\mathrm{LCO})$, a high-spin state $\left(\mathrm{t}_{2 \mathrm{~g}}{ }^{4} \mathrm{e}_{\mathrm{g}}{ }^{2}\right)$ is more favorable for cobalt ions at the surface of nano-sized LCO [87]. As the size of the LCO nanoparticle decreases, the number of surface cobalt ions increases and the $e_{g}$ filling increases as a result. As derived from the magnetization measurements, the $\mathrm{e}_{\mathrm{g}}$ was 1.0, 1.1, 1.2, and 1.27 for bulk LCO, $200 \mathrm{~nm} \mathrm{LCO,} 80 \mathrm{~nm} \mathrm{LCO}$, and $60 \mathrm{~nm}$ LCO, respectively. To investigate the intrinsic OER activity of the LCO of different sizes, the OER reaction currents of the samples were normalized to their BET surface area. It was found that $80 \mathrm{~nm}$ LCO exhibited the highest activity. The $60 \mathrm{~nm}$ LCO had a higher charge-transfer resistance because of excessive $e_{\mathrm{g}}$ filling. Therefore, the OER activity of $60 \mathrm{~nm}$ LCO was inferior to that of the $80 \mathrm{~nm} \mathrm{LCO}$. This observation is in good agreement with the Suntivich principle [17], where an e filling of $\sim 1.2$ is optimal for electrochemical OER. The results of this study demonstrate that a small particle size is not always favorable for perovskite catalysts and multiple factors should be considered when designing perovskite catalysts in the nanoscale.

\subsection{Composite Electrocatalysts Based on Perovskites}

The combination of perovskite oxides with another component that is either active in ORR/OER or provides conductive pathways is an effective way to improve the performance of the perovskite catalysts. Nanocarbons are the most commonly used composite with perovskite oxides. It has generally been thought that the role of carbon in perovskite/carbon composites is only to provide conductive pathways in oxygen electrode reactions [88,89]. The electrocatalytic performance for the ORR of carbon-supported $\mathrm{La}_{0.5} \mathrm{Sr}_{0.5} \mathrm{MnO}_{3}$ perovskite was obviously promoted [90]. A three-component-integrated catalyst (i.e., $\mathrm{LaSrMnO} / \mathrm{Fe}_{3} \mathrm{C} / \mathrm{Carbon}$ ) such as $\mathrm{La}_{0.45} \mathrm{Sr}_{0.45} \mathrm{Mn}_{0.9} \mathrm{Fe}_{0.1} \mathrm{O}_{3-\delta}$ could be fabricated by a facile surface chemistry approach, which is a feasible bifunctional catalyst for ORR and OER [91]. Additionally, there appeared to be a synergistic effect between the perovskite-oxide and the XC-72, with a change from the two-step, $2 \mathrm{e}^{-}$pathway to the $4 \mathrm{e}^{-}$transfer pathway as the carbon content increased [92]. Using $\mathrm{Ba}_{0.5} \mathrm{Sr}_{0.5} \mathrm{Co}_{0.8} \mathrm{Fe}_{0.2} \mathrm{O}_{3-\delta} /$ acetylene black carbon (BSCF/AB) as the model catalyst, Fabbri et al. proposed that there existed interactions between the carbon support and the oxide (Figure 6A) [93]. The Co K edge peak of BSCF/AB in the x-ray absorption near-edge structure (XANES) spectroscopy shifted toward the lower energy region compared to that of the pristine BSCF (Figure 6B), indicative of a lower oxidation of Co in BSCF/AB than in BSCF. The existence of a lower Co oxidation state in BSCF/AB was further supported by the XRD measurements, which showed that the BSCF/AB had a slightly higher lattice parameter. The presence of the lower Co oxidation state in BSCF/AB was attributed to the reduction of Co by carbon, which is thermodynamically favorable because Co has a high density of state near the Fermi level. The presence of lower valence Co helps to increase the intrinsic conductivity of the BSCF, thus allowing for both enhanced ORR and OER activity [94]. Additionally, carbon may effectively catalyze the disproportionation of $\mathrm{HO}_{2}^{-}$to generate $\mathrm{O}_{2}$, which might be the rate-determining step for the perovskite catalyzed ORR. Therefore, a pseudo-four-electron ORR pathway could be established on the carbon-supported perovskite [25,95]. For OER, carbon support facilitates the disproportionation of the intermediate peroxide [25]. Due to this effect, carbon support can enhance the OER activity of perovskite with limited $\mathrm{HOO}^{-}$disproportionation capability. In addition, heteroatoms in the carbon support may contribute to the stabilization of the perovskite catalyst during oxidative conditions of OER. Recently, a model describing the ORR mechanism of carbon supported perovskite catalysts was proposed [96] and suggested that, when the electrical conductivity of the perovskite phase was low, there was a polarization gradient in the catalyst at a given overpotential (Figure 6C). ORR occurred at the highly polarized region (phase boundaries where carbon and perovskite make contact) and proceeded through a four-electron pathway while the ORR at low polarization sites (electrolyte-perovskite interface) underwent a two-electron pathway. With the increase of the overpotential or addition of carbon contents, the polarization degree of the originally 
low polarization sites increased and the overall electron transfer number approached $\sim 4$. It was also suggested that adding conductive carbon contents into perovskite with low conductivity may decrease the number of rate-determining steps in ORR.
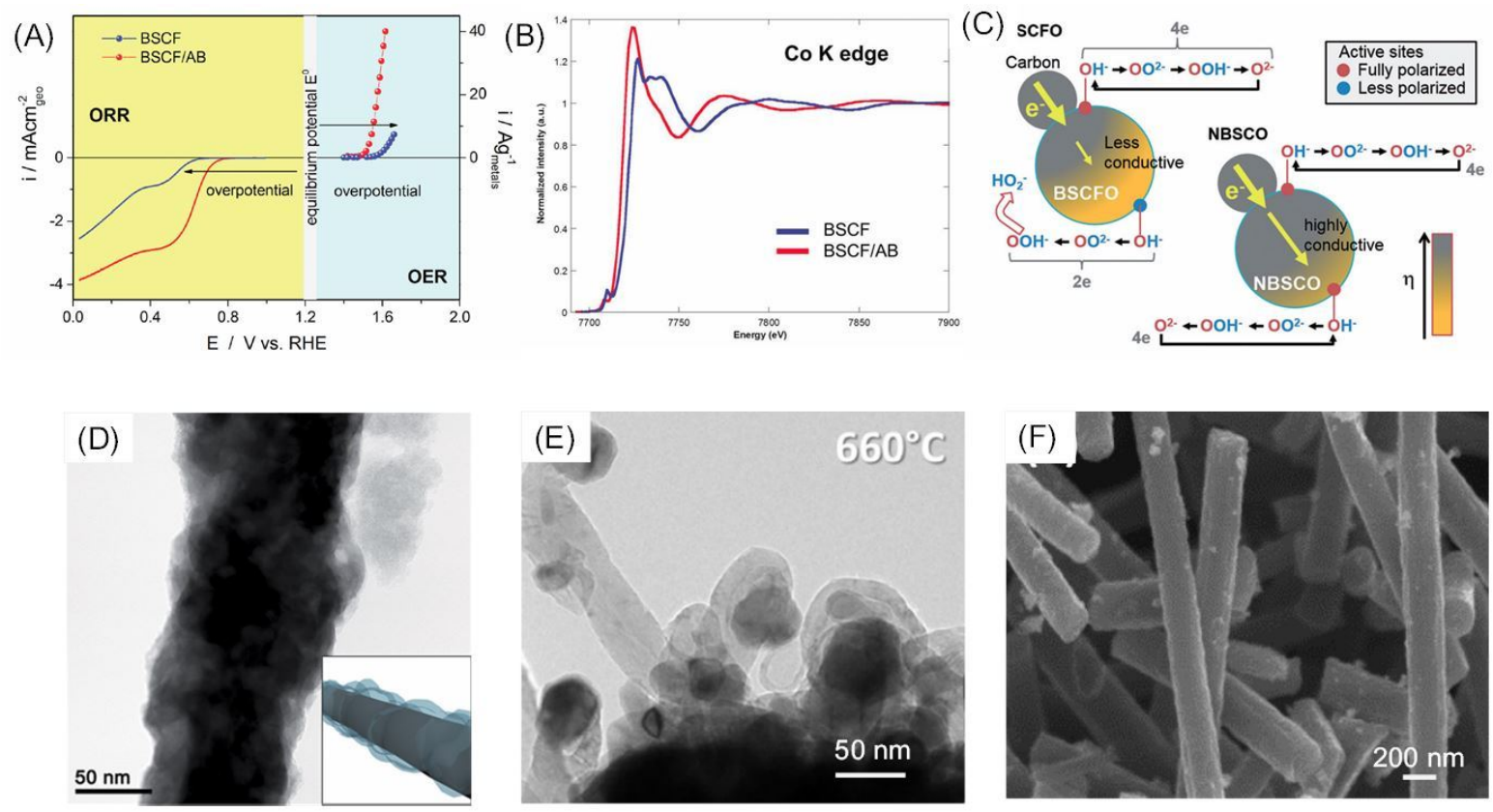

Figure 6. (A) Overall ORR and OER performance of $\mathrm{Ba}_{0.5} \mathrm{Sr}_{0.5} \mathrm{Co}_{0.8} \mathrm{Fe}_{0.2} \mathrm{O}_{3-\delta}$ (BSCF) and BSCF/acetylene black $(\mathbf{A}, \mathbf{B})$ composite in $\mathrm{O}_{2}$ saturated $0.1 \mathrm{M} \mathrm{KOH}$ solution at atating speed of $1600 \mathrm{rpm}$ with a scanning speed of $5 \mathrm{mV} \mathrm{s}^{-1}$ (adapted from [93], with permission from John Wiley and Sons, 2015). (B) XANES spectra at the Co K edge for BSCF and BSCF/AB composite (adapted from [93], with permission from John Wiley and Sons, 2015). (C) Proposed ORR mechanism on a carbon supported perovskite oxide electrocatalyst (adapted from [96], with permission from John Wiley and Sons, 2015). (D) TEM image of the cloud-like graphene nanoplatelet functionalized $\mathrm{Nd}_{0.5} \mathrm{Sr}_{0.5} \mathrm{CoO}_{3-\delta}$ nanorod electrocatalyst (adapted from [97]) (E) TEM image of the CVD grown nitrogen doped carbon coated $\mathrm{La}_{0.58} \mathrm{Sr}_{0.4} \mathrm{Fe}_{0.2} \mathrm{Co}_{0.8} \mathrm{O}_{3}$ electrocatalyst (adapted from [98], with permission from Elsevier, 2016). (F) SEM image of the nitrogen doped carbon nanotube embedded with $\mathrm{LaTi}_{0.65} \mathrm{Fe}_{0.35} \mathrm{O}_{3-\delta}$ (adapted from [99], with permission from Elsevier, 2015).

Different carbon nanostructures are employed for the construction of high-performance perovskite composite catalysts. Edge-iodinated graphene nano-pellets (IGnP) were synthesized and coated onto $\mathrm{Nd}_{0.5} \mathrm{Sr}_{0.5} \mathrm{CoO}_{3-\delta}$ (NSC) nanorods by sonication (Figure 6D) [97]. IGnP was used because of its intrinsic ORR activity, while NSC was chosen as the OER active component for its intermediate $\mathrm{e}_{\mathrm{g}}$ value $(\sim 1)$. IGnP enhances the affinity of $\mathrm{O}_{2}$ on the composite and functions as active catalytic sites. Apart from its good ORR activity, the IGnP/NSC composite also showed an enhanced OER performance when compared to the $\mathrm{IrO}_{2}$ catalyst. Carbon nanotubes have also been used to enhance the bifunctionality of perovskite oxides. The nitrogen-doped carbon nanotubes (NCNTs) were grown on $\mathrm{La}_{0.58} \mathrm{Sr}_{0.4} \mathrm{Fe}_{0.2} \mathrm{Co}_{0.8} \mathrm{O}_{3}$ (LSFC) to impart LSFC with high ORR activity (Figure 6E) [98]. Prabu et al. used an electrospinning method to produce $\mathrm{LaTi}_{0.65} \mathrm{Fe}_{0.35} \mathrm{O}_{3-\delta}$ (LTF)/nitrogen-doped carbon nanorods (Figure 6F) [99]. The nanorod exhibited a compact structure with LTF homogeneously embedded within the carbon skeleton. The LTF/N-doped carbon nanorod showed a high ORR activity through a four-electron pathway. In contrast, the LTF nanorod with a similar morphology showed a two-electron selectivity in ORR. In addition, the composite LTF demonstrated a higher OER performance as well as durability. These results clearly prove the synergistic effect between the LTF and nitrogen-doped carbon phase in the ORR and OER process. Dong-Gyu Lee et al. presented simply mixed, composite catalysts of perovskite oxide catalysts and polypyrrole ( $\mathrm{pPy}$ ). The mixture of catalyst 
particles and $\mathrm{pPy} / \mathrm{C}$ significantly reduced the overpotential of the ORR and OER [100]. Miguel A. reported dual-doped graphene/perovskite mixtures combining boron, nitrogen, phosphorous, and sulfur precursors were co-reduced with graphene oxide and mixed with $\mathrm{La}_{0.8} \mathrm{Sr}_{0.2} \mathrm{MnO}_{3}$ (LSM), which increased their bifunctional catalytic activity [101]. Due to the high intrinsic activity of the NCNTs, the composite exhibited a pronounced increase in ORR activity. A NCNT-wrapped $\mathrm{LaNiO}_{3}$ bifunctional catalyst was also developed [102]. It was believed that the NCNT framework not only provided an efficient electron transport pathway, but also facilitated the mass transfer at the electrode [102].

Combinations of ORR-active $\mathrm{La}_{0.8} \mathrm{Sr}_{0.2} \mathrm{MnO}_{3-\delta}$ (LSM) and OER-active $\mathrm{Ba}_{0.5} \mathrm{Sr}_{0.5} \mathrm{Co}_{0.8} \mathrm{Fe}_{0.2} \mathrm{O}_{3-\delta}$ (BSCF) have also been reported [103]. To exclude the effect from surface area and additives, a thin film of BSCF/LSM composite was formed on a Nb-doped $\mathrm{SrTiO}_{3}$ (NSTO) substrate by pulsed laser deposition. The BSCF coverage on LSM was varied to investigate the effect of the film composition on the overall catalytic activity toward ORR and OER. As the BSCF coverage increased, the overall ORR and OER activity of the catalyst was enhanced. The sum of the ORR and OER overpotential was as low as $0.7 \mathrm{~V}$ when the surface coverage of BSCF approached $94 \%$. Furthermore, the BSCF decoration was shown to promote the stability of the film under working conditions. Metal oxides were also compounded with perovskites to enhance the activity of perovskite catalysts. $\mathrm{A} \mathrm{MnO}_{2}-\mathrm{LaNiO}_{3}$ catalyst was reported to show enhanced ORR and OER activity when compared to both $\mathrm{MnO}_{2}$ and $\mathrm{LaNiO}_{3}$ [104]. The detailed mechanism for this enhancement is not clear yet. To improve the OER property of $\mathrm{La}_{1-x} \mathrm{Sr}_{x} \mathrm{MnO}_{3}$ (LSM), $\mathrm{NiCo}_{2} \mathrm{O}_{4}$ was homogeneously dispersed on a LSM nanorod. The combination of the ORR-active LSM and OER-active $\mathrm{NiCo}_{2} \mathrm{O}_{4}$ led to the formation of an efficient bifunctionality that showed excellent rate capability as well as cycle stability in the $\mathrm{Li}-\mathrm{O}_{2}$ battery. Daehee Lee et al. demonstrated an improvement of ORR activity in $\left(\mathrm{La}_{0.8} \mathrm{Sr}_{0.2}\right)_{0.95} \mathrm{MnO}_{3}$ perovskite thin-films placed on different oxide supports. XAS and EIS were performed to confirm that the atomic orbital interactions between the support and the catalysts sped up the exchange kinetics, thus improving the ORR electrocatalytic capability [105]. Meng Li et al. took the advantages of the junction $\mathrm{RuO}_{2}$ /perovskite with charge transfer dynamics, which enabled excellent OER activity in the solid oxide electrolysis cell (SOEC) at lower temperatures [106].

\section{Conclusions and Discussion}

The ORR and OER process are rate-determining reactions in many energy conversion processes. Thus, the development of efficient, low-cost, and bifunctional electrocatalysts is essential for the advancement of these technologies. Recently, perovskite oxides have been demonstrated as promising ORR/OER bifunctional catalysts. In addition, the performance of perovskite electrocatalysts may be further improved due to the high flexibility to tune the electronic structure of the oxides. In this review, we summarized the most recent progress on the development of high-performance perovskite oxygen electrocatalysts. As reviewed above, achievements have been accomplished in developing highly active perovskite oxide catalysts for ORR/OER. However, corresponding studies are still in their early stage and there are still many challenges to meet to apply perovskite catalysts at a large scale. Some of the issues to be addressed are as follows. First, despite the efforts to understand the ORR/OER mechanism on perovskite catalysts, it is still challenging to design and optimize perovskite catalysts rationally due to the complexity of the catalytic process. In addition, the actual performance of perovskite catalysts is influenced by multiple interplaying intrinsic factors such as electronic state and porous structure. To better clarify the ORR/OER mechanism of the perovskite oxides, well-defined model perovskites should be developed to correlate the bulk electronic structure and surface chemistry of perovskite oxides with their intrinsic electrocatalytic performances. Second, while partial substitution of A/B-site cations of perovskite oxides may enhance its activity, it may also deteriorate the stability of the perovskite. To guide the future development of partially substituted perovskite oxides, further studies are required to illustrate the relationship between the stability and activity of the perovskites. For composite perovskite electrocatalysts, the synergy between the oxide and the secondary component is not fully understood yet. Studies in this direction may help to fully utilize the synergistic effect to 
maximize the activity of the composite perovskite catalysts. Third, the ORR/OER catalytic activity of the perovskites should be further improved. Tuning the composition and surface area or using appropriate support materials have been demonstrated as effective methods to enhance the activity of perovskite oxides. Combining these methods in the development of perovskite catalysts may further boost the electrocatalytic performance. Fourth, although perovskite oxides have shown relatively high stability, it was observed in many studies that the oxides underwent structural changes during catalysis. Strategies that could inhibit this structural change would be useful for the practical applications of perovskite electrocatalysts. Finally, despite the feasibility of tuning the perovskite electrocatalyst through morphology engineering or controlling its composition, the perovskite should be designed carefully because the perovskite structure could possibly be broken down due to the stress generated during the morphology/composition control. Thus, the catalytic performance and stability of perovskite oxide should be well balanced in the design of the oxygen electrocatalyst. Although some key challenges still need to be addressed, perovskite oxygen electrocatalysts are highly promising for advanced energy conversion devices such as metal-air batteries. With the remarkable progress achieved recently and on-going research efforts, widespread applications of perovskite oxygen electrocatalysts can be expected in the near future.

Author Contributions: Conceptualization, J.L.; Writing-Original Draft Preparation, J.X., C.C., Z.H., and Y.Y.; Writing-Review \& Editing, J.L.; Project Administration, J.L. and Q.D.; Funding Acquisition, J.L. and Q.D.

Funding: This work was financially supported by the National Natural Science Foundation of China (Grant No. 51502218, 51676143), the Fundamental Research Funds for the Central Universities (WUT: 2018IB026, 2019IB003, and WUT: WUT:2019III048GX), the Excellent Dissertation Cultivation Funds of Wuhan University of Technology (2018-YS-080), the State Key Laboratory of Advanced Technology for Material Synthesis and Processing (Wuhan University of Technology, 2019-KF-10), and the Student's Platform for Innovation and Entrepreneurship Training Program. Deng acknowledges support from the "Hundred Talents Program" of the Tianjin University of Technology.

Conflicts of Interest: The authors declare no conflicts of interest.

$\begin{array}{ll}\text { Abbreviations } \\ \text { ORR } & \text { oxygen reduction reaction } \\ \text { OER } & \text { oxygen evolution reaction } \\ \text { RHE } & \text { reversible hydrogen electrode } \\ \text { TEM } & \text { transient electromagnetic method } \\ \text { SEM } & \text { scanning electron microscope } \\ \text { DFT } & \text { Density Functional Theory } \\ \text { XANES } & \text { X-ray absorption near-edge structure spectroscopy } \\ \text { XRD } & \text { X-ray diffraction } \\ \text { CVD } & \text { Chemical } \mathrm{Vapor}_{\text {Deposition }} \\ \text { BET } & \text { initials of } \mathrm{Brunauer}_{\text {Emmett and Teller }} \\ \text { CTAB } & \text { cetrimonium bromide } \\ \text { BSCF5582 } & \mathrm{Ba}_{0.5} \mathrm{Sr}_{0.5} \mathrm{Co}_{0.8} \mathrm{Fe}_{0.2} \mathrm{O}_{3-\delta} \\ \text { CYM } & \mathrm{Ca}_{0.9} \mathrm{Yb}_{0.1} \mathrm{MnO}_{3} \\ \text { LSCF } & \mathrm{LaSr}_{3} \mathrm{Co}_{\mathrm{m}} \mathrm{Fe}_{3-\mathrm{m}} \mathrm{O}_{10-\delta} \\ \text { SNCF } & \mathrm{SrNb}_{0.1} \mathrm{Co}_{0.7} \mathrm{Fe}_{0.2} \mathrm{O}_{3-\delta} \\ \text { CMO } & \mathrm{CaMnO}_{3} \\ \text { CMNO } & \mathrm{CaMn}_{0.75} \mathrm{Nb}_{0.25} \mathrm{O}_{3-\delta} \\ \text { SCP } & \mathrm{SrCo}_{0.95} \mathrm{P}_{0.05} \mathrm{O}_{3-\delta} \\ \text { LF } & \mathrm{LaFeO}_{3-\delta} \\ \text { LFRO } & \mathrm{La}_{0.9} \mathrm{Fe}_{0.92} \mathrm{Ru}_{0.08} \mathrm{O}_{3} \\ \text { LSCO } & \mathrm{La}_{1-\mathrm{x}} \mathrm{Sr}_{\mathrm{x}} \mathrm{CoO}_{3-\delta} \\ \text { SCO } & \mathrm{SrCoO}_{3-\delta} \\ \end{array}$




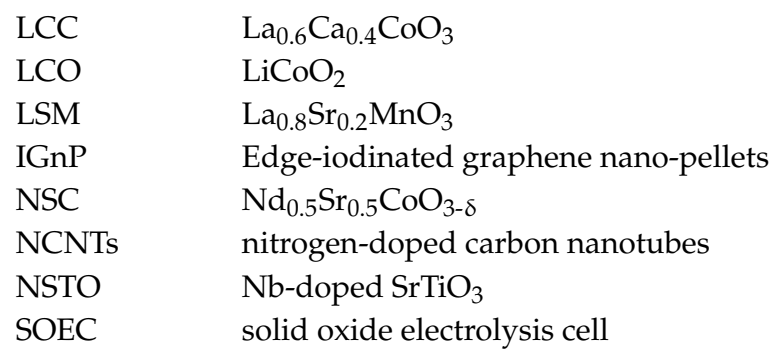

\section{References}

1. Xia, W.; Mahmood, A.; Liang, Z.; Zou, R.; Guo, S. Earth-abundant nanomaterials for oxygen reduction. Angew. Chem. Int. Edit. 2016, 55, 2650-2676. [CrossRef]

2. Wang, Z.-L.; Xu, D.; Xu, J.-J.; Zhang, X.-B. Oxygen electrocatalysts in metal-air batteries: From aqueous to nonaqueous electrolytes. Chem. Soc. Rev. 2014, 43, 7746-7786. [CrossRef] [PubMed]

3. Asefa, T. Metal-Free and Noble Metal-Free Heteroatom-Doped Nanostructured Carbons as Prospective Sustainable Electrocatalysts. Acc. Chem. Res. 2016, 49, 1873-1883. [CrossRef] [PubMed]

4. Brouzgou, A.; Song, S.Q.; Liang, Z.X.; Tsiakaras, P. Non-Precious Electrocatalysts for Oxygen Reduction Reaction in Alkaline Media: Latest Achievements on Novel Carbon Materials. Catalysts 2016, 6, 159. [CrossRef]

5. Hu, C.G.; Dai, L.M. Carbon-Based Metal-Free Catalysts for Electrocatalysis beyond the ORR. Angew. Chem. Int. Ed. 2016, 55, 11736-11758. [CrossRef]

6. Lee, D.U.; Xu, P.; Cano, Z.P.; Kashkooli, A.G.; Park, M.G.; Chen, Z.W. Recent progress and perspectives on bi-functional oxygen electrocatalysts for advanced rechargeable metal-air batteries. J. Mater. Chem. A 2016, 4, 7107-7134. [CrossRef]

7. Zhang, J.T.; Li, H.L.; Guo, P.Z.; Ma, H.Y.; Zhao, X.S. Rational design of graphitic carbon based nanostructures for advanced electrocatalysis. J. Mater. Chem. A 2016, 4, 8497-8511. [CrossRef]

8. Zhou, M.; Wang, H.L.; Guo, S.J. Towards high-efficiency nanoelectrocatalysts for oxygen reduction through engineering advanced carbon nanomaterials. Chem. Soc. Rev. 2016, 45, 1273-1307. [CrossRef]

9. Pei, Z.; Li, H.; Huang, Y.; Xue, Q.; Huang, Y.; Zhu, M.; Wang, Z.; Zhi, C. Texturing in situ: N,S-enriched hierarchically porous carbon as a highly active reversible oxygen electrocatalyst. Energy Environ. Sci. 2017, 10, 742-749. [CrossRef]

10. Yi, Y.; Tornow, J.; Willinger, E.; Willinger, M.G.; Ranjan, C.; Schlogl, R. Electrochemical Degradation of Multiwall Carbon Nanotubes at High Anodic Potential for Oxygen Evolution in Acidic Media. ChemElectroChem 2015, 2, 1929-1937. [CrossRef]

11. Speder, J.; Zana, A.; Spanos, I.; Kirkensgaard, J.J.K.; Mortensen, K.; Hanzlik, M.; Arenz, M. Comparative degradation study of carbon supported proton exchange membrane fuel cell electrocatalysts-The influence of the platinum to carbon ratio on the degradation rate. J. Power Sources 2014, 261, 14-22. [CrossRef]

12. Tanaka, H.; Misono, M. Advances in designing perovskite catalysts. Curr. Opin. Solid State Mater. Sci. 2001, 5, 381-387. [CrossRef]

13. Pena, M.A.; Fierro, J.L.G. Chemical structures and performance of perovskite oxides. Chem. Rev. 2001, 101, 1981-2017. [CrossRef]

14. Han, L.; Dong, S.J.; Wang, E.K. Transition-Metal (Co, Ni, and Fe)-Based Electrocatalysts for the Water Oxidation Reaction. Adv. Mater. 2016, 28, 9266-9291. [CrossRef]

15. Meadowcroft, D.B. Low-cost Oxygen Electrode Material. Nature 1970, 226, 847-848. [CrossRef]

16. Suntivich, J.; Gasteiger, H.A.; Yabuuchi, N.; Nakanishi, H.; Goodenough, J.B.; Shao-Horn, Y. Design principles for oxygen-reduction activity on perovskite oxide catalysts for fuel cells and metal-air batteries. Nat. Chem. 2011, 3, 546-550. [CrossRef]

17. Suntivich, J.; May, K.J.; Gasteiger, H.A.; Goodenough, J.B.; Shao-Horn, Y. A Perovskite Oxide Optimized for Oxygen Evolution Catalysis from Molecular Orbital Principles. Science 2011, 334, 1383-1385. [CrossRef]

18. Ge, X.M.; Sumboja, A.; Wuu, D.; An, T.; Li, B.; Goh, F.W.T.; Hor, T.S.A.; Zong, Y.; Liu, Z.L. Oxygen Reduction in Alkaline Media: From Mechanisms to Recent Advances of Catalysts. ACS Catal. 2015, 5, 4643-4667. [CrossRef] 
19. Cheng, F.; Shen, J.; Peng, B.; Pan, Y.; Tao, Z.; Chen, J. Rapid room-temperature synthesis of nanocrystalline spinels as oxygen reduction and evolution electrocatalysts. Nat. Chem. 2011, 3, 79-84. [CrossRef]

20. Scholz, J.; Risch, M.; Stoerzinger, K.A.; Wartner, G.; Shao-Horn, Y.; Jooss, C. Rotating Ring-Disk Electrode Study of Oxygen Evolution at a Perovskite Surface: Correlating Activity to Manganese Concentration. J. Phys. Chem. C 2016, 120, 27746-27756. [CrossRef]

21. Goodenough, J.B.; Manoharan, R.; Paranthaman, M. Surface protonation and electrochemical activity of oxides in aqueous solution. J. Am. Chem. Soc. 1990, 112, 2076-2082. [CrossRef]

22. Matsumoto, Y.; Yoneyama, H.; Tamura, H. Catalytic activity for electrochemical reduction of oxygen of lanthanum nickel oxide and related oxides. J. Electroanal. Chem. Interfac. Electrochem. 1977, 79, 319-326. [CrossRef]

23. Jung, J.I.; Jeong, H.Y.; Lee, J.S.; Kim, M.G.; Cho, J. A Bifunctional Perovskite Catalyst for Oxygen Reduction and Evolution. Angew. Chem. Int. Ed. 2014, 53, 4582-4586. [CrossRef]

24. Zhu, Y.L.; Zhou, W.; Yu, J.; Chen, Y.B.; Liu, M.L.; Shao, Z.P. Enhancing Electrocatalytic Activity of Perovskite Oxides by Tuning Cation Deficiency for Oxygen Reduction and Evolution Reactions. Chem. Mater. 2016, 28, 1691-1697. [CrossRef]

25. Hardin, W.G.; Mefford, J.T.; Slanac, D.A.; Patel, B.B.; Wang, X.Q.; Dai, S.; Zhao, X.; Ruoff, R.S.; Johnston, K.P.; Stevenson, K.J. Tuning the Electrocatalytic Activity of Perovskites through Active Site Variation and Support Interactions. Chem. Mater. 2014, 26, 3368-3376. [CrossRef]

26. Mefford, J.T.; Rong, X.; Abakumov, A.M.; Hardin, W.G.; Dai, S.; Kolpak, A.M.; Johnston, K.P.; Stevenson, K.J. Water electrolysis on La1-xSrxCoO3-delta perovskite electrocatalysts. Nat. Commun. 2016, 7, 11053. [CrossRef]

27. Hong, W.T.; Risch, M.; Stoerzinger, K.A.; Grimaud, A.; Suntivich, J.; Shao-Horn, Y. Toward the rational design of non-precious transition metal oxides for oxygen electrocatalysis. Energy Environ. Sci. 2015, 8, 1404-1427. [CrossRef]

28. Betley, T.A.; Wu, Q.; Van Voorhis, T.; Nocera, D.G. Electronic Design Criteria for O-O Bond Formation via Metal-Oxo Complexes. Inorg. Chem. 2008, 47, 1849-1861. [CrossRef]

29. Rong, X.; Parolin, J.; Kolpak, A.M. A Fundamental Relationship between Reaction Mechanism and Stability in Metal Oxide Catalysts for Oxygen Evolution. Acs Catal. 2016, 6, 1153-1158. [CrossRef]

30. Sathiya, M.; Rousse, G.; Ramesha, K.; Laisa, C.P.; Vezin, H.; Sougrati, M.T.; Doublet, M.L.; Foix, D.; Gonbeau, D.; Walker, W.; et al. Reversible anionic redox chemistry in high-capacity layered-oxide electrodes. Nat. Mater. 2013, 12, 827-835. [CrossRef]

31. Han, B.H.; Stoerzinger, K.A.; Tileli, V.; Gamalski, A.D.; Stach, E.A.; Shao-Horn, Y. Nanoscale structural oscillations in perovskite oxides induced by oxygen evolution. Nat. Mater. 2017, 16, 121-126. [CrossRef]

32. Lee, J.G.; Hwang, J.; Hwang, H.J.; Jeon, O.S.; Jang, J.; Kwon, O.; Lee, Y.; Han, B.; Shul, Y.G. A New Family of Perovskite Catalysts for Oxygen-Evolution Reaction in Alkaline Media: BaNiO3 and BaNi0.83O2.5. J. Am. Chem. Soc. 2016, 138, 3541-3547. [CrossRef]

33. Bick, D.S.; Kindsmuller, A.; Staikov, G.; Gunkel, F.; Muller, D.; Schneller, T.; Waser, R.; Valov, I. Stability and Degradation of Perovskite Electrocatalysts for Oxygen Evolution Reaction. Electrochim. Acta 2016, 218, 156-162. [CrossRef]

34. May, K.J.; Carlton, C.E.; Stoerzinger, K.A.; Risch, M.; Suntivich, J.; Lee, Y.L.; Grimaud, A.; Shao-Horn, Y. Influence of Oxygen Evolution during Water Oxidation on the Surface of Perovskite Oxide Catalysts. J. Phys. Chem. Lett. 2012, 3, 3264-3270. [CrossRef]

35. Risch, M.; Grimaud, A.; May, K.J.; Stoerzinger, K.A.; Chen, T.J.; Mansour, A.N.; Shao-Horn, Y. Structural Changes of Cobalt-Based Perovskites upon Water Oxidation Investigated by EXAFS. J. Phys. Chem. C 2013, 117, 8628-8635. [CrossRef]

36. Jung, J.I.; Jeong, H.Y.; Kim, M.G.; Nam, G.; Park, J.; Cho, J. Fabrication of Ba0.5Sr0.5Co0.8Fe0.2O3-delta Catalysts with Enhanced Electrochemical Performance by Removing an Inherent Heterogeneous Surface Film Layer. Adv. Mater. 2015, 27, 266-271. [CrossRef]

37. Hyodo, T.; Hayashi, M.; Miura, N.; Yamazoe, N. Catalytic Activities of Rare-Earth Manganites for Cathodic Reduction of Oxygen in Alkaline Solution. J. Electrochem. Soc. 1996, 143, L266-L267. [CrossRef]

38. Wang, Y.; Cheng, H.P. Oxygen Reduction Activity on Perovskite Oxide Surfaces: A Comparative First-Principles Study of LaMnO3, LaFeO3, and LaCrO3. J. Phys. Chem. C 2013, 117, 2106-2112. [CrossRef] 
39. Sunarso, J.; Torriero AA, J.; Zhou, W.; Howlett, P.C.; Forsyth, M. Oxygen Reduction Reaction Activity of La-Based Perovskite Oxides in Alkaline Medium: A Thin-Film Rotating Ring-Disk Electrode Study. J. Phys. Chem. C 2012, 116, 5827-5834. [CrossRef]

40. Zhu, C.Y.; Nobuta, A.; Nakatsugawa, I.; Akiyama, T. Solution combustion synthesis of LaMO3 (M = Fe, Co, $\mathrm{Mn})$ perovskite nanoparticles and the measurement of their electrocatalytic properties for air cathode. Int. J. Hydrog Energy 2013, 38, 13238-13248. [CrossRef]

41. Chen, D.J.; Chen, C.; Baiyee, Z.M.; Shao, Z.P.; Ciucci, F. Nonstoichiometric Oxides as Low-Cost and Highly-Efficient Oxygen Reduction/Evolution Catalysts for Low-Temperature Electrochemical Devices. Chem. Rev. 2015, 115, 9869-9921. [CrossRef]

42. Shin, B.; Choi, S.; Tak, Y. Electrocatalytic Activity of Co-based Perovskite Oxides for Oxygen Reduction and Evolution Reactions. Int. J. Electrochem. Sci. 2016, 11, 5900-5908. [CrossRef]

43. Cheng, X.; Fabbri, E.; Nachtegaal, M.; Castelli, I.E.; El Kazzi, M.; Haumont, R.; Marzari, N.; Schmidt, T.J. Oxygen Evolution Reaction on La1-xSrxCoO3 Perovskites: A Combined Experimental and Theoretical Study of Their Structural, Electronic, and Electrochemical Properties. Chem. Mater. 2015, 27, 7662-7672. [CrossRef]

44. Retuerto, M.; Pascual, L.; Calle-Vallejo, F.; Ferrer, P.; Gianolio, D.; Gonzalez Pereira, A.; Garcia, A.; Torrero, J.; Fernandez-Diaz, M.T.; Bencok, P.; et al. Na-doped ruthenium perovskite electrocatalysts with improved oxygen evolution activity and durability in acidic media. Nat. Commun. 2019, 10, 2041. [CrossRef]

45. Grimaud, A.; May, K.J.; Carlton, C.E.; Lee, Y.L.; Risch, M.; Hong, W.T.; Zhou, J.G.; Shao-Horn, Y. Double perovskites as a family of highly active catalysts for oxygen evolution in alkaline solution. Nat. Commun. 2013, 4, 2439. [CrossRef]

46. Wu, Z.L.; Sun, L.P.; Xia, T.; Huo, L.H.; Zhao, H.; Rougier, A.; Grenier, J.C. Effect of Sr doping on the electrochemical properties of bi-functional oxygen electrode PrBa1-xSrxCo2O5+delta. J. Power Sources 2016, 334, 86-93. [CrossRef]

47. Yeo, B.S.; Bell, A.T. Enhanced Activity of Gold-Supported Cobalt Oxide for the Electrochemical Evolution of Oxygen. J. Am. Chem. Soc. 2011, 133, 5587-5593. [CrossRef]

48. Gobaille-Shaw, G.P.A.; Celorrio, V.; Calvillo, L.; Morris, L.J.; Granozzi, G.; Fermin, D.J. Effect of Ba Content on the Activity of La1-xBaxMnO3 Towards the Oxygen Reduction Reaction. ChemElectroChem 2018, 5, 1922-1927. [CrossRef]

49. Guo, Y.Q.; Tong, Y.; Chen, P.Z.; Xu, K.; Zhao, J.Y.; Lin, Y.; Chu, W.S.; Peng, Z.M.; Wu, C.Z.; Xie, Y. Engineering the Electronic State of a Perovskite Electrocatalyst for Synergistically Enhanced Oxygen Evolution Reaction. Adv. Mater. 2015, 27, 5989-5994. [CrossRef]

50. Zhang, D.W.; Song, Y.F.; Du, Z.Z.; Wang, L.; Li, Y.T.; Goodenough, J.B. Active LaNi1-xFexO3 bifunctional catalysts for air cathodes in alkaline media. J. Mater. Chem. A 2015, 3, 9421-9426. [CrossRef]

51. Sun, N.A.; Liu, H.X.; Yu, Z.Y.; Zheng, Z.N.; Shao, C.Y. The electrochemical performance of La-0.Sr-6(0).Co-4(1-x) Ni (x) O-3 perovskite catalysts for Li-O-2 batteries. Ionics 2016, 22, 869-876. [CrossRef]

52. Celorrio, V.; Tiwari, D.; Fermin, D.J. Composition-Dependent Reactivity of Ba0.5Sr0.5CoxFe1-xO3-delta toward the Oxygen Reduction Reaction. J. Phys. Chem. C 2016, 120, 22291-22297. [CrossRef]

53. Su, C.; Wang, W.; Chen, Y.B.; Yang, G.M.; Xu, X.M.; Tade, M.O.; Shao, Z.P. SrCo0.9Ti0.1O3-delta As a New Electrocatalyst for the Oxygen Evolution Reaction in Alkaline Electrolyte with Stable Performance. ACS Appl. Mater. Interfaces 2015, 7, 17663-17670. [CrossRef]

54. Liu, S.; Luo, H.; Li, Y.; Liu, Q.; Luo, J.-L. Structure-engineered electrocatalyst enables highly active and stable oxygen evolution reaction over layered perovskite LaSr3Co1.5Fe1.5O10-delta. Nano Energy 2017, 40, 115-121. [CrossRef]

55. Wang, H.; Xu, W.; Richins, S.; Liaw, K.; Yan, L.; Zhou, M.; Luo, H. Polymer-assisted approach to LaCo1-xNixO3 network nanostructures as bifunctional oxygen electrocatalysts. Electrochim. Acta 2019, 296, 945-953. [CrossRef]

56. Wang, Z.D.; You, Y.; Yuan, J.; Yin, Y.X.; Li, Y.T.; Xin, S.; Zhang, D. Nickel-Doped La0.8Sr0.2Mn1-xNixO3 Nanoparticles Containing Abundant Oxygen Vacancies as an Optimized Bifunctional Catalyst for Oxygen Cathode in Rechargeable Lithium-Air Batteries. ACS Appl. Mater. Interfaces 2016, 8, 6520-6528. [CrossRef]

57. Ge, X.M.; Du, Y.H.; Li, B.; Hor TS, A.; Sindoro, M.; Zong, Y.; Zhang, H.; Liu, Z.L. Intrinsically Conductive Perovskite Oxides with Enhanced Stability and Electrocatalytic Activity for Oxygen Reduction Reactions. Acs Catal. 2016, 6, 7865-7871. [CrossRef] 
58. Zhu, Y.L.; Zhou, W.; Chen, Z.G.; Chen, Y.B.; Su, C.; Tade, M.O.; Shao, Z.P. SrNb0.1Co0.7Fe0.2O3-delta Perovskite as a Next-Generation Electrocatalyst for Oxygen Evolution in Alkaline Solution. Angew. Chem. Int. Ed. 2015, 54, 3897-3901. [CrossRef]

59. Lyu, Y.-Q.; Ciucci, F. Activating the Bifunctionality of a Perovskite Oxide toward Oxygen Reduction and Oxygen Evolution Reactions. ACS Appl. Mater. Interfaces 2017, 9, 35829-35836. [CrossRef]

60. Zhu, Y.L.; Zhou, W.; Sunarso, J.; Zhong, Y.J.; Shao, Z.P. Phosphorus-Doped Perovskite Oxide as Highly Efficient Water Oxidation Electrocatalyst in Alkaline Solution. Adv. Funct. Mater. 2016, 26, 5862-5872. [CrossRef]

61. Li, Z.; Lv, L.; Wang, J.; Ao, X.; Ruan, Y.; Zha, D.; Hong, G.; Wu, Q.; Lan, Y.; Wang, C.; et al. Engineering phosphorus-doped LaFeO3-delta perovskite oxide as robust bifunctional oxygen electrocatalysts in alkaline solutions. Nano Energy 2018, 47, 199-209. [CrossRef]

62. Jiang, Y.; Geng, Z.; Yuan, L.; Sun, Y.; Cong, Y.; Huang, K.; Wang, L.; Zhang, W. Nanoscale Architecture of $\mathrm{RuO} 2 / \mathrm{La} 0.9 \mathrm{Fe} 0.92 \mathrm{Ru} 0.08-\mathrm{xO}$-delta Composite via Manipulating the Exsolution of Low Ru-Substituted A-Site Deficient Perovskite. ACS Sustain. Chem. Eng. 2018, 6, 11999-12005. [CrossRef]

63. Velraj, S.; Zhu, J.H. Sm0.5Sr0.5CoO3-delta-A new bi-functional catalyst for rechargeable metal-air battery applications. J. Power Sources 2013, 227, 48-52. [CrossRef]

64. Zhou, W.; Zhao, M.W.; Liang, F.L.; Smith, S.C.; Zhu, Z.H. High activity and durability of novel perovskite electrocatalysts for water oxidation. Mater. Horiz. 2015, 2, 495-501. [CrossRef]

65. Chen, C.F.; King, G.; Dickerson, R.M.; Papin, P.A.; Gupta, S.; Kellogg, W.R.; Wu, G. Oxygen-deficient BaTiO3-x perovskite as an efficient bifunctional oxygen electrocatalyst. Nano Energy 2015, 13, 423-432. [CrossRef]

66. Kim, J.; Yin, X.; Tsao, K.C.; Fang, S.H.; Yang, H. Ca2Mn2O5 as Oxygen-Deficient Perovskite Electrocatalyst for Oxygen Evolution Reaction. J. Am. Chem. Soc. 2014, 136, 14646-14649. [CrossRef]

67. Peng, S.; Han, X.; Li, L.; Chou, S.; Ji, D.; Huang, H.; Du, Y.; Liu, J.; Ramakrishna, S. Electronic and Defective Engineering of Electrospun CaMnO3 Nanotubes for Enhanced Oxygen Electrocatalysis in Rechargeable Zinc-Air Batteries. Adv. Energy Mater. 2018, 8, 1800612. [CrossRef]

68. Hua, B.; Sun, Y.-F.; Li, M.; Yan, N.; Chen, J.; Zhang, Y.-Q.; Zeng, Y.; Amirkhiz, B.S.; Luo, J.-L. Stabilizing Double Perovskite for Effective Bifunctional Oxygen Electrocatalysis in Alkaline Conditions. Chem. Mater. 2017, 29, 6228-6237. [CrossRef]

69. Petrie, J.R.; Mitra, C.; Jeen, H.; Choi, W.S.; Meyer, T.L.; Reboredo, F.A.; Freeland, J.W.; Eres, G.; Lee, H.N. Strain Control of Oxygen Vacancies in Epitaxial Strontium Cobaltite Films. Adv. Funct. Mater. 2016, 26, 1564-1570. [CrossRef]

70. Wang, L.; Stoerzinger, K.A.; Chang, L.; Yin, X.; Li, Y.; Tang, C.S.; Jia, E.; Bowden, M.E.; Yang, Z.; Abdelsamie, A.; et al. Strain Effect on Oxygen Evolution Reaction Activity of Epitaxial NdNiO3 Thin Films. ACS Appl. Mater. Interfaces 2019, 11, 12941-12947. [CrossRef]

71. Petrie, J.R.; Jeen, H.; Barron, S.C.; Meyer, T.L.; Lee, H.N. Enhancing Perovskite Electrocatalysis through Strain Tuning of the Oxygen Deficiency. J. Am. Chem. Soc. 2016, 138, 7252-7255. [CrossRef]

72. Nemudry, A.; Rudolf, P.; Schöllhorn, R. Topotactic Electrochemical Redox Reactions of the Defect Perovskite SrCoO2.5+x. Chem. Mater. 1996, 8, 2232-2238. [CrossRef]

73. Petrie, J.R.; Cooper, V.R.; Freeland, J.W.; Meyer, T.L.; Zhang, Z.Y.; Lutterman, D.A.; Lee, H.N. Enhanced Bifunctional Oxygen Catalysis in Strained LaNiO3 Perovskites. J. Am. Chem. Soc. 2016, 138, 2488-2491. [CrossRef]

74. Zhu, C.; Li, H.; Fu, S.; Du, D.; Lin, Y. Highly efficient nonprecious metal catalysts towards oxygen reduction reaction based on three-dimensional porous carbon nanostructures. Chem. Soc. Rev. 2016, 45, 517-531. [CrossRef]

75. Menzel, N.; Ortel, E.; Kraehnert, R.; Strasser, P. Electrocatalysis Using Porous Nanostructured Materials. ChemPhysChem 2012, 13, 1385-1394. [CrossRef]

76. Gupta, S.; Kellogg, W.; Xu, H.; Liu, X.; Cho, J.; Wu, G. Bifunctional Perovskite Oxide Catalysts for Oxygen Reduction and Evolution in Alkaline Media. Chem. Asian J. 2016, 11, 10-21. [CrossRef]

77. Zhuang, S.X.; Huang, C.H.; Huang, K.L.; Hu, X.; Tu, F.Y.; Huang, H.X. Preparation of homogeneous nanoporous $\mathrm{La} 0.6 \mathrm{Ca} 0.4 \mathrm{CoO} 3$ for bi-functional catalysis in an alkaline electrolyte. Electrochem. Commun. 2011, 13, 321-324. [CrossRef] 
78. Ge, X.M.; Goh, F.W.T.; Li, B.; Hor, T.S.A.; Zhang, J.; Xiao, P.; Wang, X.; Zong, Y.; Liu, Z.L. Efficient and durable oxygen reduction and evolution of a hydrothermally synthesized La(Co0.55Mn0.45)(0.99)O3-delta nanorod/graphene hybrid in alkaline media. Nanoscale 2015, 7, 9046-9054. [CrossRef]

79. Bie, S.Y.; Zhu, Y.Q.; Su, J.M.; Jin, C.; Liu, S.H.; Yang, R.Z.; Wu, J. One-pot fabrication of yolk-shell structured La0.9Sr0.1CoO3 perovskite microspheres with enhanced catalytic activities for oxygen reduction and evolution reactions. J. Mater. Chem. A 2015, 3, 22448-22453. [CrossRef]

80. Jung, J.I.; Risch, M.; Park, S.; Kim, M.G.; Nam, G.; Jeong, H.Y.; Shao-Horn, Y.; Cho, J. Optimizing nanoparticle perovskite for bifunctional oxygen electrocatalysis. Energy Environ. Sci. 2016, 9, 176-183. [CrossRef]

81. Vignesh, A.; Prabu, M.; Shanmugam, S. Porous LaCo1-xNixO3-delta Nanostructures as an Efficient Electrocatalyst for Water Oxidation and for a Zinc-Air Battery. ACS Appl. Mater. Interfaces 2016, 8, 6019-6031. [CrossRef]

82. Park, H.W.; Lee, D.U.; Zamani, P.; Seo, M.H.; Zazar, L.F.; Chen, Z.W. Electrospun porous nanorod perovskite oxide/nitrogen-doped graphene composite as a bi-functional catalyst for metal air batteries. Nano Energy 2014, 10, 192-200. [CrossRef]

83. Liu, G.X.; Chen, H.B.; Xia, L.; Wang, S.Q.; Ding, L.X.; Li, D.D.; Xiao, K.; Dai, S.; Wang, H.H. Hierarchical Mesoporous/Macroporous Perovskite La0.5Sr0.5CoO3-x Nanotubes: A Bifunctional Catalyst with Enhanced Activity and Cycle Stability for Rechargeable Lithium Oxygen Batteries. ACS Appl. Mater. Interfaces 2015, 7, 22478-22486. [CrossRef]

84. Dai, J.; Zhu, Y.; Zhong, Y.; Miao, J.; Lin, B.; Zhou, W.; Shao, Z. Enabling High and Stable Electrocatalytic Activity of Iron-Based Perovskite Oxides for Water Splitting by Combined Bulk Doping and Morphology Designing. Adv. Mater. Interfaces 2019, 6, 1801317. [CrossRef]

85. Lu, F.L.; Wang, Y.R.; Jin, C.; Li, F.; Yang, R.Z.; Chen, F.L. Microporous La0.8Sr0.2MnO3 perovskite nanorods as efficient electrocatalysts for lithium air battery. J. Power Sources 2015, 293, 726-733. [CrossRef]

86. Yang, Y.B.; Yin, W.; Wu, S.T.; Yang, X.D.; Xia, W.; Shen, Y.; Huang, Y.H.; Cao, A.Y.; Yuan, Q. Perovskite-Type LaSrMnO Electrocatalyst with Uniform Porous Structure for an Efficient Li-O-2 Battery Cathode. ACS Nano. 2016, 10, 1240-1248. [CrossRef]

87. Zhou, S.M.; Miao, X.B.; Zhao, X.; Ma, C.; Qiu, Y.H.; Hu, Z.P.; Zhao, J.Y.; Shi, L.; Zeng, J. Engineering electrocatalytic activity in nanosized perovskite cobaltite through surface spin-state transition. Nat. Commun. 2016, 7, 11510. [CrossRef]

88. Wu, Y.X.; Wang, T.H.; Zhang, Y.D.; Xin, S.; He, X.J.; Zhang, D.W.; Shui, J.L. Electrocatalytic performances of g-C3N4-LaNiO3 composite as bi-functional catalysts for lithium-oxygen batteries. Sci. Rep. 2016, 6, 24314. [CrossRef]

89. Xu, Y.J.; Tsou, A.; Fu, Y.; Wang, J.; Tian, J.H.; Yang, R.Z. Carbon-Coated Perovskite BaMnO3 Porous Nanorods with Enhanced Electrocatalytic Perporites for Oxygen Reduction and Oxygen Evolution. Electrochim. Acta 2015, 174, 551-556. [CrossRef]

90. Khellaf, N.; Kahoul, A.; Naamoune, F.; Alonso-Vante, N. Electrochemistry of Nanocrystalline La0.5Sr0.5MnO3 Perovskite for the Oxygen Reduction Reaction in Alkaline Medium. Electrocatalysis 2017, 8, 450-458. [CrossRef]

91. Hua, B.; Li, M.; Luo, J.-L. A facile surface chemistry approach to bifunctional excellence for perovskite electrocatalysis. Nano Energy 2018, 49, 117-125. [CrossRef]

92. Mattick, V.F.; Jin, X.; White, R.E.; Huang, K. Understanding the role of carbon in alkaline oxygen electrocatalysis: A case study on La0.6Sr0.4CoO3-delta/Vulcan carbon composite electrocatalyst. Int. J. Hydrog. Energy 2019, 44, 2760-2769. [CrossRef]

93. Fabbri, E.; Nachtegaal, M.; Cheng, X.; Schmidt, T.J. Superior Bifunctional Electrocatalytic Activity of Ba0.5Sr0.5Co0.8Fe0.2O3-/Carbon Composite Electrodes: Insight into the Local Electronic Structure. Adv. Energy Mater. 2015, 5, 1402033. [CrossRef]

94. Wang, J.; Zhao, H.; Gao, Y.; Chen, D.J.; Chen, C.; Saccoccio, M.; Ciucci, F. Ba0.5Sr0.5Co0.8Fe0.2O3-delta on $\mathrm{N}$-doped mesoporous carbon derived from organic waste as a bi-functional oxygen catalyst. Int. J. Hydrog. Energy 2016, 41, 10744-10754. [CrossRef]

95. Nishio, K.; Molla, S.; Okugaki, T.; Nakanishi, S.; Nitta, I.; Kotani, Y. Oxygen reduction and evolution reactions of air electrodes using a perovskite oxide as an electrocatalyst. J. Power Sources 2015, 278, 645-651. [CrossRef] 
96. Lee, D.G.; Gwon, O.; Park, H.S.; Kim, S.H.; Yang, J.; Kwak, S.K.; Kim, G.; Song, H.K. Conductivity-Dependent Completion of Oxygen Reduction on Oxide Catalysts. Angew. Chem. Int. Ed. 2015, 54, 15730-15733. [CrossRef] [PubMed]

97. Kim, C.; Gwon, O.; Jeon, I.Y.; Kim, Y.; Shin, J.; Ju, Y.W.; Baek, J.B.; Kim, G. Cloud-like graphene nanoplatelets on $\mathrm{Nd} 0.5 \mathrm{Sr} 0.5 \mathrm{CoO} 3-d e l t a$ nanorods as an efficient bifunctional electrocatalyst for hybrid Li-air batteries. J. Mater. Chem. A 2016, 4, 2122-2127. [CrossRef]

98. Elumeeva, K.; Masa, J.; Sierau, J.; Tietz, F.; Muhler, M.; Schuhmann, W. Perovskite-based bifunctional electrocatalysts for oxygen evolution and oxygen reduction in alkaline electrolytes. Electrochim. Acta 2016, 208, 25-32. [CrossRef]

99. Prabu, M.; Ramakrishnan, P.; Ganesan, P.; Manthiram, A.; Shanmugam, S. LaTi0.65Fe0.35O3-delta nanoparticle-decorated nitrogen-doped carbon nanorods as an advanced hierarchical air electrode for rechargeable metal-air batteries. Nano Energy 2015, 15, 92-103. [CrossRef]

100. Lee, D.-G.; Kim, S.H.; Joo, S.H.; Ji, H.-I.; Tavassol, H.; Jeon, Y.; Choi, S.; Lee, M.-H.; Kim, C.; Kwak, S.K.; et al. Polypyrrole-assisted oxygen electrocatalysis on perovskite oxides. Energy Environ. Sci. 2017, 10, 523-527. [CrossRef]

101. Molina-Garcia, M.A.; Rees, N.V. Dual-doped graphene/perovskite bifunctional catalysts and the oxygen reduction reaction. Electrochem. Commun. 2017, 84, 65-70. [CrossRef]

102. Lee, D.U.; Park, H.W.; Park, M.G.; Ismayilov, V.; Chen, Z.W. Synergistic Bifunctional Catalyst Design based on Perovskite Oxide Nanoparticles and Intertwined Carbon Nanotubes for Rechargeable Zinc-Air Battery Applications. ACS Appl. Mater. Interfaces 2015, 7, 902-910. [CrossRef] [PubMed]

103. Risch, M.; Stoerzinger, K.A.; Maruyama, S.; Hong, W.T.; Takeuchi, I.; Shao-Horn, Y. La0.8Sr0.2MnO3-delta Decorated with Ba0.5Sr0.5Co0.3Fe0.2O3-delta: A Bifunctional Surface for Oxygen Electrocatalysis with Enhanced Stability and Activity. J. Am. Chem. Soc. 2014, 136, 5229-5232. [CrossRef] [PubMed]

104. Benhangi, P.H.; Alfantazi, A.; Gyenge, E. Manganese Dioxide-based Bifunctional Oxygen Reduction/Evolution Electrocatalysts: Effect of Perovskite Doping and Potassium Ion Insertion. Electrochim. Acta 2014, 123, 42-50. [CrossRef]

105. Lee, D.; Tan, J.; Clue, K.H.; Jeong, B.; Soon, A.; Ahn, S.-J.; Kim, J.; Moon, J. Chemically Driven Enhancement of Oxygen Reduction Electrocatalysis in Supported Perovskite Oxides. J. Phys. Chem. Lett. 2017, 8, $235-242$. [CrossRef] [PubMed]

106. Li, M.; Hua, B.; Chen, J.; Zhong, Y.; Luo, J.-L. Charge transfer dynamics in RuO2/perovskite nanohybrid for enhanced electrocatalysis in solid oxide electrolyzers. Nano Energy 2019, 57, 186-194. [CrossRef] 